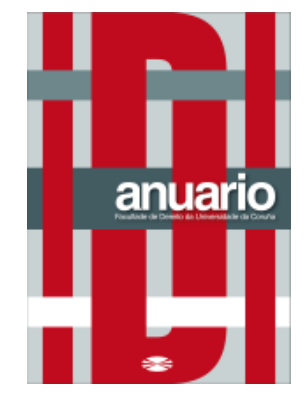

Anuario da Facultade de Dereito da Universidade da Coruña

Vol. 25 (2021), pp. 198-242

ISSNe: 2530-6324 || ISSN: 1138-039X

DOI: https://doi.org/10.17979/afdudc.2021.25.0.8805

\title{
LOS CONTRATOS DE SERVICIOS DE SEGURIDAD EN LA DOCTRINA DE LOS TRIBUNALES ADMINISTRATIVOS DE CONTRATACIÓN
}

\section{SECURITY SERVICES CONTRACTS IN THE DOCTRINE OF THE ADMINISTRATIVE PROCUREMENT TRIBUNALS}

\author{
MARÍA DEL CARMEN RODRÍGUEZ MARTÍN-RETORTILLO \\ Profesora interina de Derecho Administrativo e Investigadora \\ Universidade da Coruña \\ http://orcid.org/0000-0002-0221-7460
}

Recibido: 11/07/2021

Aceptado: 22/11/2021

Resumen: En el presente trabajo se analizan las diversas cuestiones que se plantean relativas a los contratos de servicios de seguridad por parte de los Tribunales Administrativos de Contratación, profundizando en aspectos tales como la preparación del contrato, impugnación de pliegos, requisitos de solvencia y criterios de adjudicación.

Palabras clave: Contratos, Servicios de seguridad, Doctrina, Tribunales Administrativos de Contratación, Impugnación

Abstract: This paper analyzes the various issues that are related to security service contracts by the Administrative Procurement Tribunals, deepening into aspects such as the preparation of the contract, challenge to specifications, solvency requirements and award criteria.

Keywords: Contracts, Security services, Doctrine, Administrative Procurement Tribunals, Impugnment

Sumario: I. INTRODUCCIÓN. II. SOBRE LA LEGITIMACIÓN PARA PRESENTAR EL RECURSO ESPECIAL EN MATERIA DE CONTRATACIÓN. III. EN RELACIÓN CON LA HABILITACIÓN PROFESIONAL. EXIGENCIA DE AUTORIZACIÓN PARA PRESTAR SERVICIOS DE SEGURIDAD Y 
POSIBILIDAD DE SUBCONTRATAR SERVICIOS DE ATENCIÓN DE ALARMAS. IV. REQUISITOS DE SOLVENCIA. 4.1. Requisitos de solvencia desproporcionados. Disponer de un centro de operaciones de seguridad. 4.2. Requisito de solvencia técnica admisible. Acreditar haber realizado no solo tres trabajos de seguridad y vigilancia, sino también los propios de auxiliares de sala y de transporte de caudales. 4.3. Acreditación de la solvencia. V. IMPUGNACIÓN DE PLIEGOS. 5.1. Criterios de valoración o adjudicación. A. Pliegos. Criterio de valoración desproporcionado: el disponer de más de 2000 empleados de seguridad privada en la Comunidad de Madrid. B. Pliegos. Criterio de valoración. Valoración de la experiencia del personal adscrito. C. Pliegos. Criterio de valoración. La ponderación respecto de los criterios relacionados con la calidad debe representar al menos el $51 \%$ de la puntuación total. Determinación de si los criterios sociales son criterios de calidad. D. Pliegos. Criterio de valoración. Establecimiento de certificados de calidad como criterios de adjudicación. Falta de vinculación con el objeto. E. Pliegos. Impugnación de criterios de valoración. Asignación de puntos a una mejora del sistema de remuneración y de la cuantía salarial de los trabajadores. F. Pliego. Criterio de adjudicación. De valoración automática: disponibilidad en la localidad donde se ubica el Centro de Artes Visuales de la Fundación Helga de Alvear (Cavha) de una cámara acorazada para la custodia de obras de arte. 5.2. Impugnación de pliego. Funciones de seguridad $y$ funciones de auxiliares de control. VI. IMPUGNACIÓN DEL PRESUPUESTO BASE DE LICITACIÓN, VALOR ESTIMADO Y PRECIO PORQUE NO HAN SIDO CALCULADOS CORRECTAMENTE POR EL ÓRGANO DE CONTRATACIÓN. VII. MODIFICACIÓN SIGNIFICATIVA DE PLIEGO DE SEGURIDAD. VIII. PRESENTACIÓN DE OFERTA EN LA PLATAFORMA DE CONTRATACIÓN POR LICITADOR DISTINTO DEL QUE PRESENTÓ LA DOCUMENTACIÓN DE LA OFERTA. ERROR EN LA PRESENTACIÓN ELECTRÓNICA DE LA OFERTA. 8.1. Impugnación de la exclusión por no alcanzar la puntuación mínima. 8.2. Impugnación de la exclusión de un licitador. IX. PROPUESTA DE ADJUDICACIÓN DEL CONTRATO FORMULADA POR LA MESA DE CONTRATACIÓN. NO SUSCEPTIBLE DE RECURSO. X. IMPUGNACIÓN DE LA ADJUDICACIÓN. DISCRECIONALIDAD TÉCNICA. 10.1. Impugnación de adjudicación. Precio totalizado y no individualizado. 10.2. Impugnación de adjudicación. Alegación de supuesta información privilegiada. 10.3. Impugnación de adjudicación. Alegación del licitador recurrente sobre especificación del tiempo de respuesta. 10.4. Impugnación valoración sin justificación. 10.5. Impugnación de valoración de medios diferentes a los exigidos en el PPT. 10.6. Impugnación de valoración. Ausencia de arbitrariedad o discriminación. 10.7. Impugnación de valoración. No valorable la simple repetición del pliego. XI. SUBROGACIÓN DE TRABAJADORES DE EMPRESAS DE SEGURIDAD. XII. INEXISTENCIA DE OFERTA ANORMALMENTE BAJA. XIII. CONCLUSIONES.

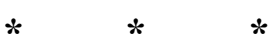

I. INTRODUCCIÓN 
Las empresas de seguridad privada y el personal que las integran realizan una labor fundamental de apoyo a las Administraciones Públicas para la protección de personas y bienes. Se regulan en la Ley 5/2014, de 4 de abril, de Seguridad Privada ${ }^{1}$ (en adelante LSP). Como indica su exposición de motivos, "cada vez más, la seguridad privada se considera una parte indispensable del conjunto de medidas destinadas a la protección de la sociedad y a la defensa de los derechos y legítimos intereses de los ciudadanos". A nivel contractual los servicios de seguridad se centraron inicialmente en aspectos relativos a la clasificación de empresas de servicios ${ }^{2}$, aunque ahora no es exigible la obligatoriedad de la clasificación, tampoco en contratos de determinada cuantía ${ }^{3}$, y después se han recogido los contratos de seguridad en otras materias ${ }^{4}$.

Cada vez es más frecuente que las Administraciones Públicas y demás entidades del Sector Público utilicen la contratación de servicios de seguridad ${ }^{5}$, dando lugar a una

${ }^{1} \mathrm{BOE} \mathrm{n}^{\circ} 83$, de 5 de abril de 2014.

Artículo 1. Objeto:

"Esta ley tiene por objeto regular la realización y la prestación por personas privadas, físicas o jurídicas, de actividades y servicios de seguridad privada que, desarrollados por éstos, son contratados, voluntaria u obligatoriamente, por personas físicas o jurídicas, públicas o privadas, para la protección de personas y bienes. Igualmente regula las investigaciones privadas que se efectúen sobre aquéllas o éstos. Todas estas actividades tienen la consideración de complementarias y subordinadas respecto de la seguridad pública". Vid. R. Decreto 2364/1994, de 9 de diciembre, por el que se aprueba el Reglamento de Seguridad Privada (vigente en cuanto no se oponga a la Ley $5 / 2014$ ).

${ }^{2}$ Ya se recogía en la Orden de 24 de noviembre de 1982 (grupo C, subgrupo 2), modificada por la Orden de 30 de enero de 1991 (Grupo M. Servicios especializados. Subgrupo 2. Servicios de seguridad, custodia y protección) y Resolución de la Dirección General de Patrimonio de 17 de mayo de 1991, y art. 37 del Reglamento General de la Ley de Contratos de las Administraciones Públicas (RGLCAP).

${ }^{3}$ Vid. Ley $9 / 2017$, de 8 de noviembre, de Contratos del Sector Público, por la que se transponen al ordenamiento jurídico español las Directivas del Parlamento Europeo y del Consejo 2014/23/UE y 2014/24/UE, de 26 de febrero de 2014 (en adelante LCSP), art. 77.1.b).

${ }^{4}$ Vid. Ley 13/1995, de 18 de mayo, de Contratos de las Administraciones Públicas (en adelante LCAP), art. 207, Categorías de los contratos (23. Investigación y seguridad, excepto furgones blindados); Real Decreto Legislativo 2/2000, de 16 de junio, por el que se aprueba el texto refundido de la Ley de Contratos de las Administraciones Públicas (en adelante TRLCAP), art. 206, Categorías de los contratos (23. Investigación y seguridad, excepto furgones blindados); Ley 30/2007 de 30 de octubre, de Contratos del Sector Público, Anexo II Servicios a los que se refiere el artículo 10, Categoría 23 (Servicios de investigación y seguridad, excepto los servicios de furgones blindados); Real Decreto Legislativo 3/2011, de 14 de noviembre, por el que se aprueba el texto refundido de la Ley de Contratos del Sector Público (en adelante TRLCSP), Anexo II Servicios a que se refiere el artículo 10, Categoría 23 (Servicios de investigación y seguridad, excepto los servicios de furgones blindados); LCSP, art. $145.3 \mathrm{~g}$ ) "Igualmente, en el caso de los contratos de servicios de seguridad privada deberá aplicarse más de un criterio de adjudicación"; LCSP, Anexo IV Servicios especiales a que se refieren los artículos $22.1 \mathrm{c}), 135.5$ y la Disposición adicional trigésima sexta (Códigos CPV 79700000-1 a 79721000-4. Servicios de investigación y seguridad, Servicios de seguridad, Servicios de vigilancia de sistemas de alarma, Servicios de vigilancia).

${ }^{5}$ Artículo 2 LSP. Definiciones:

"1. Seguridad privada: el conjunto de actividades, servicios, funciones y medidas de seguridad adoptadas, de forma voluntaria u obligatoria, por personas físicas o jurídicas, públicas o privadas, realizadas o prestados por empresas de seguridad, despachos de detectives privados y personal de seguridad privada para hacer frente a actos deliberados o riesgos accidentales, o para realizar averiguaciones sobre personas y bienes, con la finalidad de garantizar la seguridad de las personas, proteger su patrimonio y velar por el normal desarrollo de sus actividades. 
amplia gama de recursos y resoluciones de los Tribunales administrativos de contratación sobre diversas cuestiones que analizaremos en el presente estudio. También existe sobre esta materia una doctrina de las Juntas Consultivas de Contratación ${ }^{6}$ y jurisprudencia al respecto ${ }^{7}$.

Sobre este tema es relevante el reciente informe 1439 del Tribunal de Cuentas de 6 de septiembre de 2021 relativo a fiscalización de las contrataciones de los servicios de seguridad privada llevadas a cabo por los Ministerios del Área de Administración Económica del Estado y sus organismos dependientes durante los ejercicios 2016 a 2019.

\section{SOBRE LA LEGITIMACIÓN PARA PRESENTAR EL RECURSO ESPECIAL EN MATERIA DE CONTRATACIÓN}

El art. 48 de la LCSP $^{8}$ introduce dos novedades respecto al art. 42 del TRLCSP.

2. Actividades de seguridad privada: los ámbitos de actuación material en que los prestadores de servicios de seguridad privada llevan a cabo su acción empresarial y profesional.

3. Servicios de seguridad privada: las acciones llevadas a cabo por los prestadores de servicios de seguridad privada para materializar las actividades de seguridad privada".

6 Vid. Informe 1/2007, de 25 de enero de 2007, de la Junta Consultiva de Contratación Administrativa del Gobierno de Canarias. Aspectos relativos a determinadas condiciones establecidas en las licitaciones para la adjudicación de contratos de servicios de vigilancia y seguridad; Dictamen 7/2010, de 15 de marzo, del Consejo Consultivo de Navarra, sobre Resolución del contrato de los servicios de seguridad y vigilancia de centros dependientes del Servicio Navarro de Salud-Osasunbidea (Expediente: 49/2009).

${ }^{7}$ Audiencia Nacional (Sala de lo Contencioso-administrativo, Sección 4a), Sentencia de 29 de mayo de 2019, Rec. 370/2016; Tribunal Superior de Justicia de Extremadura (Sala de lo Contenciosoadministrativo), Sentencia 332/2017, de 27 de septiembre de 2017, Rec. 345/2016; Tribunal Superior de Justicia de Canarias de Las Palmas de Gran Canaria (Sala de lo Contencioso-administrativo, Sección $1^{\text {a }}$ ), Sentencia 397/2013, de 15 de octubre de 2013, Rec. 706/2011; Tribunal Superior de Justicia de la Comunidad Valenciana (Sala de lo Contencioso-administrativo, Sección 5a), Sentencia 505/2020, de 15 de junio de 2020, Rec. 22/2017; Tribunal Supremo (Sala Tercera, de lo Contencioso-administrativo, Sección 4a), Sentencia 1345/2020, de 19 de octubre de 2020, Rec. 7382/2018; Tribunal Superior de Justicia de Castilla-La Mancha (Sala de lo Contencioso-administrativo, Sección $1^{\mathrm{a}}$ ), Sentencia 4/2020, de 24 de enero de 2020, Rec. 497/2017; Tribunal Superior de Justicia de Canarias de Las Palmas de Gran Canaria (Sala de lo Contenciosoadministrativo, Sección 1ª), Sentencia 603/2018, de 28 de noviembre de 2018, Rec. 270/2017; Tribunal Superior de Justicia de Les Illes Balears (Sala de lo Contencioso-administrativo), Sentencia 48/2020, de 10 de febrero de 2020, Rec. 189/2018; Tribunal Superior de Justicia de La Rioja (Sala de lo Contenciosoadministrativo), Sentencia 64/2018, de 21 de febrero de 2018, Rec. 28/2017; Tribunal Superior de Justicia de Madrid (Sala de lo Contencioso-administrativo, Sección 3a), Sentencia 94/2019, de 8 de febrero de 2019, Rec. 722/2017; Tribunal Superior de Justicia de Canarias de Las Palmas de Gran Canaria (Sala de lo Contenciosoadministrativo, Sección 1a), Sentencia 315/2020 de 3 de marzo de 2020, Rec. 504/2017; Tribunal Superior de Justicia de la Comunidad Valenciana (Sala de lo Contencioso-administrativo, Sección 5a), Sentencia 814/2020, de 13 de octubre de 2020, Rec. 99/2017; Tribunal Superior de Justicia de Madrid (Sala de lo Contencioso-administrativo, Sección 3a), Sentencia 136/2018, de 23 de febrero de 2018, Rec. 337/2017.

${ }^{8}$ Artículo 48 LCSP. Legitimación:

"Podrá interponer el recurso especial en materia de contratación cualquier persona física o jurídica cuyos derechos o intereses legítimos, individuales o colectivos, se hayan visto perjudicados o puedan resultar afectados, de manera directa o indirecta, por las decisiones objeto del recurso.

Estarán también legitimadas para interponer este recurso, contra los actos susceptibles de ser recurridos, las organizaciones sindicales cuando de las actuaciones o decisiones recurribles pudiera deducirse fundadamente que estas implican que en el proceso de ejecución del contrato se incumplan por el empresario las obligaciones sociales o laborales respecto de los trabajadores que participen en la realización de la prestación. 
Por un lado, amplía el ámbito de la legitimación del recurso especial en materia de contratación, no ya sólo a aquellos que resulten perjudicados en sus derechos e intereses legítimos (tal y como establecía el TRLCSP) sino que se especifica que tales derechos e intereses legítimos pueden ser "individuales o colectivos" y, además, se abre a la afectación indirecta, "puedan resultar afectados, de manera directa o indirecta por las decisiones objeto del recurso" ".

La falta de legitimación es causa de inadmisión del recurso (art. 55 b) LCSP) ${ }^{10}$. seguridad:

Hay dos ámbitos donde se manifiesta especialmente en materia de contratos de

A.- Por una parte, las organizaciones sindicales ${ }^{11}$. Tal y como establece el art. 48 LCSP se circunscribe a las actuaciones o decisiones recurribles en que pudiera deducirse fundadamente que estas implican que en el proceso de ejecución del contrato se incumplan por el empresario las obligaciones sociales o laborales respecto de los trabajadores que participen en la realización de la prestación.

Como se dijo en la STC 210/1994, de 11 de julio, FJ 4 -recuerda la Resolución del TACRC 496/2020 - "la función constitucionalmente atribuida a los sindicatos no alcanza a transformarlos en guardianes abstractos de la legalidad, cualesquiera que sean las

En todo caso se entenderá legitimada la organización empresarial sectorial representativa de los intereses afectados".

9 La regulación en materia de legitimación en el ámbito del recurso especial en materia de contratación, se completa con el requisito de que debe figurar en el escrito de interposición del recurso el documento o documentos que acrediten la legitimación del actor cuando la ostente por habérsela transmitido otro por herencia o por cualquier otro título (art. $51.1 \mathrm{~b}$ ) LCSP).

${ }^{10}$ Artículo 55 b) LCSP:

"la falta de legitimación del recurrente o de acreditación de la representación de la persona que interpone el recurso en nombre de otra, mediante poder que sea suficiente a tal efecto".

${ }^{11}$ El Tribunal Constitucional ha elaborado una consolidada doctrina sobre el reconocimiento a los sindicatos de un interés legítimo en la impugnación de resoluciones y actos administrativos que les confiere legitimación para el acceso a la jurisdicción. Así, la STC 148/2014, de 22 de septiembre, reitera que:

"En relación con la legitimación de los sindicatos, en la STC 202/2007, de 24 de septiembre, sistematizando nuestra doctrina, recordamos que ha de partirse de "un reconocimiento abstracto o general de la legitimación de los sindicatos para impugnar ante los órganos del orden jurisdiccional contencioso-administrativo decisiones que afecten a los trabajadores, funcionarios públicos y personal estatutario. Así, hemos dicho que los sindicatos desempeñan, tanto por el reconocimiento expreso de la Constitución (arts. 7 y 28) como por obra de los tratados internacionales suscritos por España en la materia, una función genérica de representación y defensa de los intereses de los trabajadores que no descansa sólo en el vínculo de la afiliación, sino en la propia naturaleza sindical del grupo. La función de los sindicatos, desde la perspectiva constitucional, no es únicamente la de representar a sus miembros a través de esquemas propios del Derecho privado, pues cuando la Constitución y la Ley los invisten con la función de defender los intereses de los trabajadores, les legitiman para ejercer aquellos derechos que, aun perteneciendo en puridad a cada uno de los trabajadores, sean de necesario ejercicio colectivo, sin estar condicionados a la relación de pretendido apoderamiento ínsita en el acto de afiliación. Por esta razón, es posible, en principio, reconocer legitimado al sindicato para accionar en cualquier proceso en que estén en juego intereses colectivos de los trabajadores (por todas, SSTC 101/1996, de 11 de junio, 203/2002, de 28 de octubre, 142/2004, de 13 de septiembre, y 28/2005, de 14 de febrero)". (Resolución del TACRC 496/2020). 
circunstancias en que ésta pretenda hacerse valer. La conclusión es que la legitimación procesal del sindicato en el orden jurisdiccional contencioso-administrativo se ha de localizar en la noción de interés profesional o económico; concepto este que ha de entenderse referido en todo caso a un interés en sentido propio, cualificado o específico, y que doctrinal y jurisprudencialmente viene identificado en la obtención de un beneficio o la desaparición de un perjuicio en el supuesto de que prospere la acción intentada, y que no necesariamente ha de revestir un contenido patrimonial. Esto es, tiene que existir un vínculo especial y concreto entre el sindicato (sus fines, su actividad, etc.) y el objeto del debate en el pleito de que se trate (SSTC 7/2001, de 15 de enero, FJ 5; y 24/2001, de 29 de enero, FJ 5)"12.

En la Resolución del Tribunal Administrativo Central de Recursos Contractuales (TACRC) 496/2020, ante el recurso presentado por las secciones de tres organizaciones sindicales, contra el anuncio de la licitación convocada por la Autoridad Portuaria de Bilbao para contratar el "Servicio de seguridad y servicios auxiliares de carácter accesorio a las terminales de cruceros de la Autoridad Portuaria de Bilbao", se indica que las organizaciones sindicales recurren la licitación con base en el incumplimiento de obligaciones sociales o laborales respecto del personal laboral de la APB (esto es, a los trabajadores del poder adjudicador) y no respecto de los trabajadores que participen en la adjudicación del contrato (esto es, a los trabajadores del adjudicatario). Pues bien, estas alegaciones se orientan a una defensa genérica de la legalidad, no existiendo una mínima justificación de la relación entre la pretendida legitimación del sindicato con el fondo de los motivos de impugnación aludidos ni con lo dispuesto en el art. 48 de la LCSP $^{13}$.

B.- Legitimación de licitadores clasificados en tercer lugar. Por otra parte, los Tribunales de contratación consideran que carecen de legitimación los licitadores clasificados en tercer lugar. En este sentido, la Resolución del Tribunal Administrativo de Contratación Pública de la Comunidad de Madrid nº134/2018, de 9 de mayo de 2018, indica que "este Tribunal considera que cabe cuestionarse la legitimación activa de la recurrente, ya que el reproche que realiza la misma es genérico y se encuentra anudado a la consideración de que al ser la oferta económica de las clasificadas en mejor posición a la suya más baja, necesariamente incumplen el convenio colectivo de aplicación, argumento que al no resultar acorde con los hechos probados en el expediente respecto de la oferta clasificada en tercer lugar, justo por encima de la recurrente, determina que aun de estimarse el recurso por las razones que invoca, al no ser aplicables las mismas a la oferta de Cont. Emp. Seguridad, S.A., en ningún caso devendría adjudicataria del contrato".

${ }^{12}$ Vid. Sentencias del Tribunal Constitucional n²10/94, 257/88 y 106/96.

${ }^{13}$ Añade "la recurrente no realiza un mínimo esfuerzo para tratar de justificar la necesaria conexión que debe existir, para admitir la legitimación del sindicato, entre los supuestos incumplimientos de los criterios de valoración que alegan y un hipotético incumplimiento en la ejecución del contrato de la normativa laboral o de los derechos y garantías de los trabajadores de las empresas de seguridad. Por todo ello, no puede reconocerse legitimación a las organizaciones sindicales actoras para interponer el recurso que nos ocupa y, por tanto procede inadmitir el recurso sin necesidad de hacer ningún pronunciamiento respecto al fondo de la cuestión planteada". 
En igual sentido se pronuncia el Tribunal Administrativo de Contratación Pública de la Comunidad Autónoma de Galicia (en adelante TACGAL) ${ }^{14}$, al afirmar que "debemos partir del principio de que la legitimación activa comporta que la anulación del acto impugnado produzca de modo inmediato un efecto positivo (beneficio) o la evitación de un efecto negativo (perjuicio) actual o futuro, pero cierto. Supone, en definitiva, que la resolución administrativa impugnada pueda repercutir, directa o indirectamente, pero de modo efectivo y acreditado, es decir, no meramente hipotético, potencial y futuro, en la esfera jurídica de quien alega su legitimación".

El TACGAL en otra Resolución ${ }^{15}$ se reafirma en esta doctrina al indicar que la estimación de su recurso en nada mejoraría su posición en la licitación, ya que en ningún caso adquiriría la condición de adjudicataria, por lo que, no obteniendo ningún beneficio en su esfera jurídica con la estimación de su impugnación se concluye que carece de interés legítimo y, por lo tanto, de legitimación, por lo que procede la inadmisión del recurso.

\section{EN RELACIÓN CON LA HABILITACIÓN PROFESIONAL. EXIGENCIA DE AUTORIZACIÓN PARA PRESTAR SERVICIOS DE SEGURIDAD Y POSIBILIDAD DE SUBCONTRATAR SERVICIOS DE ATENCIÓN DE ALARMAS}

Las empresas de Seguridad tienen que estar autorizadas para el ejercicio de su actividad $^{16}$ y estar inscritas en el Registro correspondiente. Por lo tanto, este es un requisito de habilitación profesional a que se refiere el art. 65.2 de la LCSP ${ }^{17}$. Para la prestación del servicio de atención de alarmas las empresas tienen que estar autorizadas. Pero la cuestión es si las empresas de seguridad pueden subcontratar este servicio de atención de alarmas, o incluso si puede establecerse en el pliego la prohibición de esta subcontratación.

La Resolución del TACRC n 446/2021, de 23 de abril de 2021, se pronuncia sobre la cuestión de la habilitación profesional. Básicamente fundamenta el recurrente su impugnación en que la empresa adjudicataria no ostenta la correspondiente autorización en materia de seguridad privada para la prestación del servicio de Central de Alarmas.

La cuestión que debe dilucidarse en este recurso es por tanto si, en este caso, era o no necesario que la empresa adjudicataria del contrato de seguridad privada contase con una concreta autorización para la prestación relativa al servicio de central de alarmas, o bien era suficiente con la autorización prevista en los pliegos (cláusula 6.8 PCAP) para

${ }^{14}$ Resolución del TACGAL n³8/2019, de 12 de febrero de 2019.

${ }^{15}$ Resolución del TACGAL nº125/2018, de 13 de diciembre de 2018.

${ }^{16}$ Artículo 18.1 LSP. Autorización administrativa:

“1. Para la prestación de servicios de seguridad privada, las empresas de seguridad privada deberán obtener autorización administrativa y serán inscritas de oficio en el registro correspondiente, de acuerdo con el procedimiento que se determine reglamentariamente".

${ }^{17}$ Artículo 65.2 LCSP:

"2. Los contratistas deberán contar, asimismo, con la habilitación empresarial o profesional que, en su caso, sea exigible para la realización de las prestaciones que constituyan el objeto del contrato".

Vid. Artículos 39.2, 79.2, 96.1, 131.3, 318, 321.2 y 339.1 LCSP. 
prestar el servicio de "Vigilancia y protección de bienes, establecimientos, espectáculos, certámenes o convenciones" del art. 1.a) del Reglamento de seguridad privada ${ }^{18}$.

Para prestar el servicio aquí controvertido relativo a la central de alarmas la ley exige inequívocamente la mencionada autorización administrativa (en este sentido art. 18 de la Ley 5/2014, de seguridad privada, en relación al art. 5 de la misma Ley; al igual que art. 2 del Reglamento en relación al art. 1 del mismo). La empresa adjudicataria no dispone de autorización para prestar el servicio relativo a la letra f) del art. 1 del Reglamento de seguridad privada (documento $\mathrm{n}^{\circ} 2$ del recurso, y documento $\mathrm{n}^{\circ} 4$ de los incluidos en la "documentación administrativa del adjudicatario" en el expediente administrativo (elemento 31)), aunque sí está autorizada como empresa de seguridad privada, inscrita en el registro correspondiente del Ministerio del Interior, y autorizada para desarrollar la actividad exigida en los pliegos (la de la letra a) del art. 1 del Reglamento de seguridad privada).

La cuestión controvertida, de acuerdo con el escrito de recurso, se centra en la posible vulneración de la regla en materia de subcontratación establecida en el art. 14.3 del Reglamento de seguridad privada ${ }^{19}$.

El Tribunal indica que "ni la Ley ni el Reglamento prohíben la contratación de actividades que no se pueden prestar por no contar con autorización para ello, sino más exactamente prestar la actividad en sí, razón por la cual debemos concluir que es acorde a la normativa en vigor la contratación con empresas sólo parcialmente autorizadas siempre que conste el compromiso de subcontratar la prestación de la actividad no autorizada con una empresa que posea la pertinente habilitación".

Lo anterior implica que el sistema de prestación del servicio relativo a la central receptora de alarma por parte de la adjudicataria mediante el recurso a otra empresa autorizada para prestarlo debe considerarse válido a juicio de este Tribunal ${ }^{20}$.

Como conclusión podemos concretar que la Administración puede contratar a una empresa de seguridad para que preste los servicios de seguridad, pudiendo esta empresa

${ }^{18}$ Efectivamente, los pliegos únicamente exigieron la autorización para prestar la actividad de seguridad privada "del apartado 1 a) del artículo 1 del Reglamento de Seguridad Privada", no exigiendo la relativa al apartado 1.f) del mismo artículo, relativa a la "Explotación de centrales para la recepción, verificación y transmisión de las señales de alarmas y su comunicación a las Fuerzas y Cuerpos de Seguridad, así como prestación de servicios de respuesta cuya realización no sea de la competencia de dichas Fuerzas y Cuerpos", a la que alude el recurrente.

19 "Los servicios y actividades de seguridad deberán ser realizados directamente por el personal de la empresa contratada para su prestación, no pudiendo ésta subcontratarlos con terceros, salvo que lo haga con empresas inscritas en los correspondientes Registros y autorizadas para la prestación de los servicios o actividades objeto de subcontratación, y se cumplan los mismos requisitos y procedimientos prevenidos en este Reglamento para la contratación. La subcontratación no producirá exoneración de responsabilidad de la empresa contratante".

${ }^{20}$ En el mismo sentido se pronunció también este Tribunal en la Resolución 569/2018, de 12 de junio, que reitera a su vez lo dicho en la Resolución 334/2017, de 6 de abril y en la Resolución 26/2016, de 15 de enero. 
subcontratar el servicio de atención de alarmas con una empresa autorizada, sin que sea requisito que la primera tenga esta autorización.

Sin embargo, por ejemplo la Resolución del Tribunal Administrativo de Contratación Pública de la Comunidad de Madrid n³7/2019, de 30 de enero 2019, manifiesta que dado que la propuesta como adjudicataria "no dispone de autorización administrativa para ello, el cumplimiento del contrato debería realizarse mediante subcontratación, que, como hemos analizado, está expresamente prohibida, por lo que incumple lo previsto en la cláusula $6^{\mathrm{a}}$ del PCAP en relación con la cláusula 1.7 del mismo, al no disponer de la habilitación empresarial y profesional exigida" 21 .

Como reflexión en relación con esta Resolución entendemos que el Tribunal ha considerado que el pliego podía prohibir la subcontratación, circunstancia ahora no recogida en la LCSP (art. 215), salvo que de manera motivada se hubiera considerado tarea crítica a tenor del art. $215.2 \mathrm{e})^{22}$.

El Tribunal Administrativo de Contratos Públicos de la Comunidad Autónoma de Canarias $^{23}$, señaló igualmente que "no cabe otra cosa que concluir, en la misma línea doctrinal sentada por el TACRC (valgan como ejemplo las resoluciones invocadas por el órgano de contratación, número 0026/2016, de 15 de enero y 1035/2016, de 16 de diciembre), "que es plenamente ajustado a la normativa en vigor con relación a la contratación de servicios de vigilancia privada, el realizarla con una empresa habilitada como tal aun cuando no tenga la autorización específica para alguna de las actividades incluidas en la prestación siempre que estas se desarrollen por una empresa subcontratada que sí cuente con ella", dado que "ni la Ley ni el Reglamento prohíben la contratación de actividades que no se pueden prestar por no contar con autorización para ello, sino más exactamente prestar la actividad en sí, razón por la cual debemos concluir que es acorde a la normativa en vigor la contratación con empresas sólo parcialmente autorizadas siempre que conste el compromiso de subcontratar la prestación de la actividad no autorizada con una empresa que posea la pertinente habilitación".

Sin embargo, el Tribunal Administrativo de Contratación Pública de Madrid hace una interpretación más restrictiva, pues señala que el recurrente alega que: "Se establece en el Capítulo I, sobre las Características del Contrato, en la Cláusula 1.19 4) del Pliego de Cláusulas Administrativas Particulares (PCAP), como Condición especial de ejecución del contrato "4) Conexión a la CRA de alarmas y servicio de acuda". Añadiendo que "Las obligaciones contenidas en este apartado tienen el carácter de obligación contractual esencial, a los efectos establecidos en el artículo 211 de la LCSP y conforme a lo dispuesto en la cláusula que regula la resolución del contrato del presente pliego".

A continuación, manifiesta que "Por su parte, en el Pliego de Prescripciones Técnicas Particulares (PPTP) que han de regir la ejecución del contrato de servicios, se

${ }^{21}$ En términos similares, vid. Resolución del Tribunal Administrativo de Contratación Pública de la Comunidad de Madrid nº51/2021, de 4 de febrero de 2021.

${ }^{22}$ Ratifica lo que afirmamos la Resolución del TACRC n ${ }^{\circ} 1205 / 2021$, de 16 de septiembre.

${ }^{23}$ Resolución 004/2021, de 14 de enero. 
establece en el punto '2.8. CARACTERÍSTICAS DE LA VIGILANCIA'. En este sentido debemos recordar que los servicios de vigilancia y seguridad deben ser prestados por empresas autorizadas por la Dirección General de la Policía, para la vigilancia, instalación y mantenimiento y explotación de centrales para la conexión y, de acuerdo con el punto 2.8 los servicios de conexión a CRA y de respuesta ante situaciones de alarma se encuentran vinculados y por ello, no es posible que sean prestados de forma separada o independiente. A su vez en el mismo Capítulo I, sobre las Características del Contrato, en la cláusula 22 del PCAP establece claramente: '22.- Subcontratación. Procede: No'. En definitiva, nos encontramos que la Conexión a la Central Receptora de Alarmas (CRA) es una obligación de carácter esencial del contrato y a su vez el PCAP establece que no es posible subcontratar ninguno de los servicios contratados".

El Tribunal concluye que "Respecto al lote 3 "Dotar del servicio de vigilancia y seguridad a la sede D.A.T. Madrid-Sur - C/ Maestro, nº19, 28914-Leganés (Madrid)", se acredita que dispone de un sistema de alarma anti intrusión conectada a la Central de Recepción de Alarmas, por lo que el adjudicatario tiene obligación de proceder a la conexión, mantenimiento y conservación sin acudir a la subcontratación. La propia empresa reconoce en su escrito de 11 de enero de 2019 la necesidad de subcontratar la conexión al CRA para la prestación del servicio de este lote.

Dado que no dispone de autorización administrativa para ello, el cumplimiento del contrato debería realizarse mediante subcontratación, que, como hemos analizado, está expresamente prohibida, por lo que incumple lo previsto en la cláusula $6^{\mathrm{a}}$ del PCAP en relación con la cláusula 1.7 del mismo, al no disponer de la habilitación empresarial y profesional exigida" ${ }^{24}$.

\section{REQUISITOS DE SOLVENCIA}

\subsection{Requisitos de solvencia desproporcionados. Disponer de un centro de operaciones de seguridad}

En un pliego de servicios de seguridad y vigilancia y auxiliares de sala para la Fundación Colección Thyssen-Bornemisza, se exigía como requisito de solvencia que las empresas dispusieran de la propiedad un centro de operaciones de seguridad ${ }^{25}$.

${ }^{24}$ La Resolución del Tribunal Administrativo de Contratación Pública de la Comunidad de Madrid $\mathrm{n}^{\circ} 51 / 2021$, de 4 de febrero de 2021 señala, ante otro caso similar que "el recurso se reduce al análisis relativo a la falta de habilitación de la adjudicataria para CRA y la inadmisión de subcontratar esta prestación, incluida en el objeto del contrato, que se deriva del primer párrafo de la cláusula 1.23 del PCAP, pues como menciona la recurrente y ha mantenido este Tribunal en anteriores Resoluciones (299/2019 de 10 de julio, y 375/2019 de 10 de septiembre) el artículo 14.3 del Reglamento de Seguridad Privada prevé la posibilidad de subcontratar los servicios y actividades de seguridad cuando se haga con empresas inscritas en los correspondientes Registros y autorizadas para la prestación de los servicios o actividades objeto de subcontratación, y se cumplan los mismos requisitos y procedimientos prevenidos en este Reglamento para la contratación, sin que se produzca exoneración de responsabilidad de la empresa contratante".

${ }^{25}$ Así, la cláusula 4.1.4.d) PCAP impone la aportación de: "Certificado que acredite la propiedad de al menos un Centro de Operaciones de Seguridad (SOCs), no externalizados. Un Centro de Operaciones de Seguridad (COS), (SOC en inglés) es una central de seguridad informática que previene, monitorea y controla la seguridad en las redes y en Internet. Los servicios que presta van desde el diagnóstico de vulnerabilidades 
En relación con esta cuestión, la Resolución del TACRC nº345/2021, de 9 de abril de 2021, ha señalado "la exigencia de la propiedad de un Centro de Operaciones de Seguridad, constituye un requisito de solvencia desproporcionado, al requerir que todas las empresas que quieran participar en la licitación tengan ya, con anterioridad a la presentación de solicitudes, en propiedad un Centro de Operaciones de Seguridad", afirmando que "los argumentos ofrecidos por el órgano de contratación no permiten entender que el requisito de solvencia técnica requerido cumple con los parámetros de proporcionalidad exigidos, ya que no se justifica que el disponer en propiedad del centro resulte imprescindible para garantizar la adecuada prestación del contrato, de forma que dicha exigencia no garantiza el cumplimiento de los principios rectores de la contratación administrativa, en especial, ser un campo abierto a la máxima concurrencia competitiva garante de los principios de legalidad y no discriminación entre los licitadores (artículo 1 y 132 de la LCSP)".

\subsection{Requisito de solvencia técnica admisible. Acreditar haber realizado no solo tres trabajos de seguridad y vigilancia, sino también los propios de auxiliares de sala y de transporte de caudales}

Ante el recurso planteado por un licitador que cuestionaba la ausencia de la exigencia de solvencia técnica en servicios auxiliares y transporte de caudales, en la Resolución del TACRC $\mathrm{n}^{\circ} 345 / 2021$, de 9 de abril de 2021, se ha afirmado que "de todos modos, tampoco es del todo cierto que la Fundación haya obviado todo requisito de solvencia para los servicios de auxiliares de sala. En efecto, en la Cláusula Particular 4.1.4.a) se requiere una "relación de los principales servicios realizados en los últimos tres años, de igual o similar naturaleza que los que constituyen el objeto del contrato". Por tanto, en la medida en que la Cláusula Particular 11 (Objeto del Contrato) establece que "el objeto del Contrato es la prestación (...) de los servicios de Seguridad y Vigilancia y Auxiliares de Sala, así como el transporte de caudales", para cumplir con este requisito de solvencia, los licitadores no sólo deben acreditar haber realizado tres trabajos de seguridad y vigilancia, sino también los propios de auxiliares de sala y de transporte de caudales.

En definitiva, todos los criterios de solvencia técnica que la Fundación ha incluido en los pliegos tienen una clara relación con los servicios objeto de contratación, son proporcionados y están justificados, bien por tratarse de requisitos que impone la ley, o bien porque sirven para verificar que el licitador que finalmente vaya a prestar los servicios".

Como conclusión podemos afirmar que por el Tribunal se admiten estos tres tipos de prestación para exigirlos como requisitos de solvencia técnica porque tienen relación con los servicios que se van a prestar en el contrato y son proporcionados.

\subsection{Acreditación de la solvencia}

hasta la recuperación de desastres, pasando por la respuesta a incidentes, neutralización de ataques, programas de prevención, administración de riesgos y alertas de antivirus informáticos”. 
Resulta relevante la resolución del TACRC $n^{\circ} 902 / 2021$, de 22 de julio, relativa a la forma y plazo de acreditar la solvencia económica y técnica.

\section{IMPUGNACIÓN DE PLIEGOS}

\subsection{Criterios de valoración o adjudicación}

A. Pliegos. Criterio de valoración desproporcionado: el disponer de más de 2000 empleados de seguridad privada en la Comunidad de Madrid

En el pliego se puntuaba dentro de los criterios de valoración el disponer de más de 2000 empleados de seguridad, otorgando 4 puntos a quien tuviera este requisito ${ }^{26}$.

Como señala el TACRC en la Resolución n³45/2021, de 9 de abril de 2021, asiste la razón a la asociación recurrente cuando considera desproporcionado el criterio de valoración — disponer de más de 2.000 empleados de seguridad privada en la Comunidad de Madrid - , para el contrato de servicio de vigilancia y seguridad que se presta con un total de 25 vigilantes de seguridad (Fundamento de Derecho Quinto, apartado XIII). Aunque ocasionalmente se pueda necesitar un reforzamiento de los servicios, resulta patente la amplia desproporción entre la plantilla actual y la establecida como criterio de valoración; como señalaba este Tribunal en otra de sus resoluciones (número 228/2011): "No requiere mucha argumentación la existencia de una amplia desproporción entre ambas cifras y la consecuente falta de relación de esta exigencia del pliego con el objeto del contrato". Dicho criterio de valoración contraviene lo dispuesto en el art. 145.5 LCSP ${ }^{27}$.

Por otra parte, dicho criterio nada aporta en relación con la determinación de la calidad de la oferta, al referirse más a las características de las empresas licitadoras, aspectos que sólo son aceptables como criterio de solvencia.

Recordemos que la Sentencia del Tribunal de Justicia de la UE (Sala Primera), de 24 de enero de 2008 (Asunto C-532/06, Lianakis y otros), declaró que "se excluyen como

\footnotetext{
${ }^{26}$ El pliego decía:
}

"Relación de medios humanos a disposición del servicio (4 puntos). La Fundación valorará con 4 puntos las propuestas que acrediten la disposición de 2.000 empleados de seguridad privada en la Comunidad de Madrid para la ejecución del contrato".

${ }^{27}$ Artículo 145.5 LCSP:

"Los criterios a que se refiere el apartado 1 que han de servir de base para la adjudicación del contrato se establecerán en los pliegos de cláusulas administrativas particulares o en el documento descriptivo, y deberá figurar en el anuncio que sirva de convocatoria de la licitación, debiendo cumplir los siguientes requisitos:

a) En todo caso estarán vinculados al objeto del contrato, en el sentido expresado en el apartado siguiente de este artículo.

b) Deberán ser formulados de manera objetiva, con pleno respeto a los principios de igualdad, no discriminación, transparencia y proporcionalidad, y no conferirán al órgano de contratación una libertad de decisión ilimitada.

c) Deberán garantizar la posibilidad de que las ofertas sean evaluadas en condiciones de competencia efectiva e irán acompañados de especificaciones que permitan comprobar de manera efectiva la información facilitada por los licitadores con el fin de evaluar la medida en que las ofertas cumplen los criterios de adjudicación. En caso de duda, deberá comprobarse de manera efectiva la exactitud de la información y las pruebas facilitadas por los licitadores". 
'criterios de adjudicación' aquellos criterios que no van dirigidos a identificar la oferta económicamente más ventajosa, sino que están vinculados, en esencia, a la apreciación de la aptitud de los licitadores para ejecutar el contrato en cuestión".

Asimismo, aun cuando se vinculara de algún modo a la oferta, como valoración de mayores medios ofertados, el disponer de esa plantilla en la Comunidad de Madrid, otorgaría una preferencia a la empresa con arraigo territorial en dicha Comunidad, asimilándose tal exigencia a una limitación a la concurrencia.

Es decir, esta Resolución aplica el principio de proporcionalidad, pues el criterio se refiere a las características de las empresas y no a criterios de calidad, pues basta la exigencia de adscripción de medios personales para prestar el servicio.

B. Pliegos. Criterio de valoración. Valoración de la experiencia del personal adscrito

La valoración de la experiencia ha experimentado una evolución en la normativa contractual. Así, inicialmente no era posible valorarla como criterio de adjudicación, por considerarla una cualidad propia de la empresa licitadora y no de la oferta, y en este sentido se han pronunciado diversas Juntas consultivas de contratación administrativa ${ }^{28}$ y el Tribunal Supremo (STS de 16 de febrero de 2010 y STS de 7 de junio de 2012) e incluso alguna sentencia del Tribunal de Justicia de la Unión Europea (STJUE de 9 de octubre de 2014). Sin embargo, a raíz de la Sentencia del Tribunal de Justicia de la Unión Europea C601/13, de 26 de marzo de 2015, el criterio del TJUE se modificó y se consideró que en ciertos tipos de contratos y en determinados supuestos, sí cabía la consideración de la experiencia como criterio de adjudicación ${ }^{29}$. Esta doctrina se incorporó a la Directiva 2014/24/UE del Parlamento Europeo y del Consejo, de 26 de febrero de 2014 (Considerando 94 y art. 69) y también a la LCSP (art. 145).

En el supuesto que vamos a analizar, la entidad recurrente solicita la nulidad del criterio objetivo de valoración de las ofertas del Anexo XII del PCAP, consistente en valorar con 30 puntos la experiencia del personal adscrito al contrato, premiando la aportación de personal que tenga mayor número de años de experiencia. Resumidamente, fundamenta la nulidad de dicho criterio porque infringe la LCSP al utilizar la valoración de la experiencia como criterio de adjudicación y al no respetar los requisitos de los criterios de valoración previstos en el art. $145^{30}$.

28 Vid. Informe 50/06, de 12 de diciembre de 2006, de la Junta Consultiva de Contratación Administrativa del Estado e Informe 6/2011, de 5 de julio, de la Junta Consultiva de Contratación Administrativa de la Generalitat de Cataluña.

${ }^{29}$ En este sentido, es importante la doctrina del TACRC (por ejemplo, la Resolución 129/2019).

${ }^{30}$ Artículo 145.2 LCSP:

"2. ${ }^{\circ}$ La organización, cualificación y experiencia del personal adscrito al contrato que vaya a ejecutar el mismo, siempre y cuando la calidad de dicho personal pueda afectar de manera significativa a su mejor ejecución". 
El tribunal ${ }^{31}$ considera que "no concurren en los pliegos, ni antes en la memoria explicativa, aspectos que permitan deducir que la calidad de la ejecución de este contrato, dependa de manera determinante, de la experiencia profesional de los trabajadores encargados de su ejecución ${ }^{32}$. Esa supuesta calidad no se configura como una característica intrínseca de la oferta, que es lo que se valora al aplicar los criterios de adjudicación de acuerdo con el artículo 145.2 2 de la LCSP. Consecuentemente, en este caso, la valoración de la experiencia como criterio de adjudicación vulnera los principios básicos de la contratación administrativa, en concreto, los de libre concurrencia, de igualdad de trato y de transparencia".

C. Pliegos. Criterio de valoración. La ponderación respecto de los criterios relacionados con la calidad debe representar al menos el $51 \%$ de la puntuación total. Determinación de si los criterios sociales son criterios de calidad

Se denuncia que la ponderación respecto de los criterios relacionados con la calidad debe representar al menos el $51 \%$ de la puntuación total, y los criterios sociales no son criterios de calidad $^{33}$.

El Tribunal considera que no cabe estimar el alegato del recurso, ya que el art. 145.2 de la LCSP dispone que la mejor relación calidad-precio se evaluará con arreglo a criterios económicos y cualitativos, añadiendo que los criterios cualitativos podrán incluir, entre otros, aspectos sociales, por lo que estos evalúan la calidad.

D. Pliegos. Criterio de valoración. Establecimiento de certificados de calidad como criterios de adjudicación. Falta de vinculación con el objeto

El recurrente considera que estar en posesión de determinados certificados acreditativos del cumplimiento de normas de garantía de calidad no cumple el art. 145 de la LCSP.

El tribunal declara que "podemos afirmar que tal como aparecen configurados en la LCSP los certificados de calidad están contemplados como forma de acreditar la solvencia técnica de las empresas; que los criterios de adjudicación han de estar vinculados con el objeto del contrato; y que esta exigencia de vinculación debe interpretarse en el sentido de referirse a las características de la oferta que los licitadores presentan, es decir sobre cómo van a ejecutar las prestaciones propias del contrato. Encontrándonos ante un acuerdo marco de servicios, y de conformidad con lo establecido en el artículo 145.6 de la LCSP, se considerará que un criterio de adjudicación está vinculado al objeto del contrato

31 Resolución del Tribunal Administrativo de Contratos Públicos de la Comunidad Autónoma de Canarias $n^{\circ} 163 / 2021$, de 10 de junio.

32 En este sentido la JCCPE en su Informe 108/18 señala que la experiencia del personal de las licitadoras sí se puede tomar en consideración como criterio de adjudicación siempre que se cumplan dos condiciones:

1- Que el personal que se mencione en los pliegos esté encargado de la ejecución efectiva del contrato.

2- Que la calidad del personal empleado pueda afectar de manera significativa a la ejecución del contrato.

${ }^{33}$ Vid. Resolución del Tribunal Administrativo de Recursos Contractuales de la Junta de Andalucía, $n^{\circ} 11 / 2021$, de 21 de enero de 2021 . 
cuando se refiera o integre las prestaciones que deban realizarse en virtud de dicho contrato, en cualquiera de sus aspectos y en cualquier etapa de su ciclo de vida, incluidos los factores que intervienen en el proceso específico de prestación de los servicios" 34 .

Pues bien, atendiendo a los criterios expuestos, y a la vista del contenido de la memoria justificativa, el Tribunal considera que "no queda acreditada la vinculación de los certificados que se exigen con el objeto del contrato, de forma que los establecidos como criterios de adjudicación en el PCAP hacen referencia a características o cualidades de las empresas, no a la concreta oferta que pueda presentarse en la presente licitación para ser adjudicatario del acuerdo marco".

En este sentido debe destacarse como el legislador al trasponer la Directiva 2014/24/UE, y para determinar la vinculación con el objeto contrato, ha hecho referencia a las prestaciones del contrato. En efecto, el art. 67.3 de la Directiva establece que "Se considerará que los criterios de adjudicación están vinculados al objeto del contrato público cuando se refieran a las obras, suministros o servicios que deban facilitarse en virtud de dicho contrato (...)" mientras que el art. 145.6 de la LCSP dispone que "Se considerará que un criterio de adjudicación está vinculado al objeto del contrato cuando se refiera o integre las prestaciones que deban realizarse en virtud de dicho contrato (...)”.

En este sentido, es relevante la resolución del TACRC n ${ }^{\circ} 1245 / 2021$, de 23 de septiembre, que considera la improcedencia de la utilización de los criterios de adjudicación consistentes en estar en posesión de 2 determinados certificados de calidad (Certificado AENOR de conformidad del sistema de gestión profesional y deontológico de los servicios de seguridad privada en base al Reglamento SP-2012-0001 y Certificación de gestión de la calidad en los servicios de seguridad privada GCSSP001:2012), sin perjuicio de su posible utilización como medios para acreditar la solvencia técnica.

E. Pliegos. Impugnación de criterios de valoración. Asignación de puntos a una mejora del sistema de remuneración y de la cuantía salarial de los trabajadores

En numerosas Resoluciones se ha planteado la cuestión de si es posible asignar puntuación a una mejora del sistema de remuneración y de la cuantía salarial de los trabajadores afectos a la prestación del servicio, sobre el salario bruto contemplado en el Convenio colectivo de aplicación.

Es habitual que la empresa recurrente considere que estos criterios de adjudicación son contrarios a Derecho, pues, no tiene una relación directa con el objeto del contrato y no respeta el Derecho europeo, especialmente el principio de no discriminación entre los licitadores ${ }^{35}$.

La Resolución del TACRC 235/2019, de 8 de marzo de 2019, hace referencia a la Resolución del Tribunal Administrativo de Recursos Contractuales del Parlamento de Andalucía 4/2018, estimatoria de un recurso similar al presente, en la que se citaban las

\footnotetext{
${ }^{34}$ Ibidem.

${ }^{35}$ Vid. Resolución del TACRC nº471/2020, de 26 de marzo de 2020.
} 
Sentencias del Tribunal Superior de Justicia de Madrid números 220/2017 y 136/2018, que afirman que un criterio de valoración consistente en el compromiso de aplicar un aumento porcentual del salario base de los vigilantes de seguridad que presten el servicio objeto de contratación, respecto del salario base estipulado por el Convenio Colectivo Estatal de Empresas de Seguridad, no ofrece una relación directa con el objeto del contrato, y no es una cláusula social de las que la Directiva 2014/24/UE permite incluir como criterio de adjudicación.

La segunda de las sentencias citadas señala que este criterio de adjudicación "puede producir discriminación en relación con las empresas que no se rijan por el Convenio Estatal, en detrimento de las ofertas de los participantes que tengan suscrito un convenio de empresa propio", y que "el incremento salarial de los trabajadores en contratos de este tipo en que los costes salariales constituyen la parte esencial del precio fomentará la realización de ofertas económicamente más elevadas cuanto mayores sean también los costes salariales y viceversa, traduciéndose esta exigencia en la presentación de ofertas más caras y menos beneficiosas económicamente para la Administración, en contra del espíritu que ha de regir en la ponderación de las ofertas para seleccionar un adjudicatario en los artículos 150 y siguientes del TRLCSP, cuya finalidad es que resulte elegido el licitador cuya oferta sea económicamente la más ventajosa para la Administración, y sin que el servicio se vea beneficiado, y con evidente discriminación entre las empresas con mayores o menores posibilidades económicas, aunque todas hayan tenido ya que acreditar la solvencia económica como condición previa”.

En la Resolución 235/2019 el Tribunal interpretó que la expresión "socialmente sostenibles y justas" del art. 145.6 de la LCSP se refiere al nivel mínimo establecido por la normativa de aplicación, lo que, en el caso de los salarios, alude al salario mínimo interprofesional, o al fijado en el convenio de empresa o en el convenio colectivo sectorial de aplicación: "Estos niveles salariales son los socialmente justos y sostenibles; por debajo de ellos, no lo son".

Recordaba también el Tribunal en la Resolución 235/19 que el art. 1 de la LCSP proclama como uno de los principios que deben informar la contratación del sector público la estabilidad presupuestaria y el control del gasto, en consonancia con lo dispuesto en el art. 31 de la Constitución. Y que "Es evidente, tal y como afirma la mencionada Sentencia del TSJ de Madrid 136/2018, que el criterio de adjudicación recurrido supone un incremento automático del precio del contrato para la Administración, sin una contraprestación que redunde directamente en un mejor rendimiento del servicio tal y como está definido en las prescripciones técnicas, por lo que este criterio vulnera los proclamados principios de eficiencia, economía y control del gasto".

Además, el Tribunal consideró, en la aludida Resolución 235/2019, que el criterio de adjudicación recurrido parece atentatorio contra la libertad de empresa, en el marco de la economía de mercado, que reconoce el art. 38 de la Constitución, "suponiendo una injerencia indebida en la relación entre la empresa y sus trabajadores, por referirse a niveles distintos a los que el artículo 145.6 de la LCSP considera referentes especiales de los 
criterios de adjudicación de carácter social: el nivel socialmente sostenible y justo. Es decir, el nivel legalmente establecido" 36 .

Los razonamientos expuestos son plenamente trasladables al supuesto que se examina en la Resolución del TACRC nº 471/2020, de 26 de marzo de 2020.

El órgano de contratación argumenta que unas condiciones salariales mejoradas respecto de las establecidas en el Convenio colectivo de aplicación, que sería el mínimo exigido, darían lugar a una menor rotación del personal y que la productividad, la calidad y la seguridad del servicio serían mayores. El Tribunal considera que no cabe afirmar categóricamente que una mejora de las condiciones salariales del personal afecto a la prestación del servicio redunde necesariamente en una mejora de la calidad del servicio prestado, ni en términos generales, ni atendiendo a las concretas condiciones exigidas para ejecutarlo en el PPT. Por el contrario, el Tribunal no aprecia cómo esas mejoras salariales pueden estar vinculadas con el objeto del contrato en estricto sentido, esto es, con la prestación del servicio de vigilancia y seguridad objeto de licitación. No mejoran, per se, el rendimiento o la calidad de la ejecución, tal y como está configurada en el PPT, ni permiten medir los niveles de rendimiento valorando comparativamente las distintas ofertas, tal y como exige la Directiva 2014/24/UE para que un criterio de adjudicación resulte admisible. Sin perjuicio de lo anterior, y aun cuando pudiera ser dudoso si el criterio social de adjudicación impugnado está vinculado al objeto del contrato (quod non), no cabe duda de que el mismo resulta discriminatorio con respecto de aquellos licitadores que, cumpliendo escrupulosamente el Convenio colectivo aplicable, paguen a sus empleados conforme al mismo. Como indicó el Tribunal en la Resolución 235/2019, este es un criterio similar al que se contiene en la STJUE de 20 de septiembre de 1988 en el caso Beentjes vs Países Bajos (Asunto 31/87) y al que ya mantuvo la Junta Consultiva en su Informe 3/2009.

F. Pliego. Criterio de adjudicación. De valoración automática: disponibilidad en la localidad donde se ubica el Centro de Artes Visuales de la Fundación Helga de Alvear (Cavha) de una cámara acorazada para la custodia de obras de arte

La cuestión a analizar es si la fijación de un criterio de valoración automática consistente en la disponibilidad por parte del adjudicatario de una cámara acorazada está vinculada o no al objeto del contrato.

Por ello, la recurrente impugna el criterio de adjudicación de valoración automática "Disponibilidad en la localidad del CAVHA de cámara acorazada para la custodia de obras de arte" 37 , al considerar que no tiene vinculación con el objeto del contrato y que al mismo tiempo afecta al principio de igualdad de trato entre los licitadores ${ }^{38}$.

\footnotetext{
${ }^{36}$ Cabe señalar que el criterio manifestado por este Tribunal en la tan citada Resolución 235/2019 ha sido reiterado en posteriores ocasiones, como las Resoluciones 388/2019, de 17 de abril, 897/2019, de 31 de julio, 1267/2019, de 11 de noviembre, 1449/2019, de 11 de diciembre, o 14/2020, de 9 de enero.

${ }^{37}$ Establecido en el punto 7.1.1.B.4) del Pliego.

${ }^{38}$ Este criterio tiene una ponderación máxima en el pliego de 15 puntos sobre un total de 90 puntos si solo consideramos los criterios objetivos, o sobre 100 puntos si incluimos también los criterios sujetos a juicio de valor.
} 
La Comisión Jurídica de Extremadura ${ }^{39}$ desestima el recurso y admite que se pueda establecer como criterio de valoración la disponibilidad en la localidad de una cámara acorazada para la custodia de obras de $\operatorname{arte}^{40}$ y así señala que "teniendo en cuenta que el objeto del contrato que se licita es un servicio de vigilancia y seguridad del Centro de Artes Visuales de la Fundación Helga de Alvear, cuya actividad principal, según la documentación obrante en el expediente remitido, es la de museo o centro de exposiciones, albergando en consecuencia obras de arte, la inclusión como criterio de adjudicación la opción de que las empresas licitadoras oferten la disponibilidad de cámara acorazada para la custodia de esas obras de arte, custodia que justifica el informe del órgano de contratación: "los servicios de seguridad y vigilancia se desarrollan precisamente en un museo de obras de arte, donde la protección de las mismas es primordial y donde para alcanzar la total seguridad de las piezas artísticas que tiene a su cargo, ante situaciones de obras de arte en tránsito o ante cualquier circunstancia puntual, puede ser requerida la custodia de las mismas en una cámara acorazada.

La existencia de cámara acorazada además adquiere su total y definitivo sentido si se produjera cualquier situación de emergencia que hiciera necesaria la evacuación del edificio para garantizar la adecuada salvaguarda de bienes con tan elevado valor patrimonial", no se puede considerar ajeno a la prestación a contratar, es más se puede afirmar que la complementa perfectamente en pos de prever posibles situaciones de futuro, acreditándose perfectamente la vinculación necesaria al objeto del contrato definido en el oportuno pliego, pues si dicha prestación consiste en prestar labores de vigilancia y seguridad, abarcando tanto a bienes muebles como inmuebles, la posibilidad de poder hacer uso de una cámara acorazada en momentos concretos, entendemos enriquece la oferta a seleccionar".

Para reforzar la argumentación la Comisión Asesora indica que "máxime teniendo en cuenta que los pliegos no exigen la tenencia de la cámara acorazada al momento de licitar, sino que estaríamos ante una oferta de la misma, cuya posesión, por cualquier régimen, se desplazaría a la ejecución del contrato".

Y añade que "ello sin ignorar que la ponderación de este criterio impugnado, en contradicción con lo alegado en el recurso, tiene una relevancia de un máximo de 15 puntos sobre un total de 100, ponderación razonable en función de su aporte al contrato".

Esta Resolución nos plantea la duda si se puede admitir la disponibilidad de la cámara si no está incluido su coste en el presupuesto del contrato, aunque el Tribunal no entra en esta cuestión.

${ }^{39}$ La Comisión Jurídica de Extremadura es el órgano competente a tenor de lo establecido en la disposición adicional primera.6 de la Ley $2 / 2021$, de 21 de mayo, de defensa, asistencia jurídica y comparecencia en juicio de la administración de la Comunidad Autónoma de Extremadura (BOE nº 151 , de 25 de junio de 2021).

${ }^{40}$ Resolución de la Comisión Jurídica de Extremadura n²8/2018, de 16 de agosto. 


\subsection{Impugnación de pliego. Funciones de seguridad y funciones de auxiliares de control}

Vamos a analizar la posibilidad de incluir varias prestaciones de vigilancia y seguridad y de personal auxiliar y la posibilidad de subcontratación. El recurrente alega que "puede concluirse que el objeto del contrato del presente recurso incluye prestaciones de vigilancia y seguridad y otras de personal auxiliar de control y que las funciones de vigilancia y seguridad están reservadas en exclusiva a las empresas de seguridad y que éstas empresas únicamente pueden ejercer los servicios que enumera la Ley de Seguridad Privada considerados como de seguridad. No resulta posible que una misma empresa de seguridad incluya en su objeto social la realización de funciones de auxiliares de control, pues son prestaciones incompatibles con las de seguridad porque la regulación legal impide".

Termina a este respecto manifestando que "En síntesis, el problema, como decimos, es que el presente contrato no distingue servicios de seguridad de los que no lo son, y exige su prestación íntegra por únicamente vigilantes de seguridad ( $\sin$ armas, pero con habilitación -últimos párrafos del punto 5.2 del PPT, en consonancia con la obligación legal de la LSP-), por tanto, resulta improcedente la configuración del contrato, dado que, además, el régimen laboral y de convenio de un tipo de personal y de otro, es distinto, afectando al régimen de subrogación, funciones de cada puesto, categorías, salarios, etc. Los pliegos que rigen la presente adjudicación, permiten la subcontratación, pero no la indican expresamente para los servicios auxiliares, que no podrían ser prestados por empresas de seguridad privada, ya que exceden de los que el art. 6 de la LSP define como complementarios, como hemos visto".

Es de destacar que la organización sindical mantiene que "las funciones de los vigilantes de seguridad son exclusivas y excluyentes y que únicamente puede realizar aquellas funciones que la normativa en materia de seguridad privada les atribuye (artículo 32.1 de la LSP)". Posteriormente, viene a hacer mención del art. 6 de la LSP que regula las actividades compatibles pero que a su juicio plantea problemas de interpretación al ponerlo en relación con el art. 32.2 de la LSP, y finalmente termina manifestando que las actividades del art. 6.2 "podrán ser prestadas por dichas empresas de seguridad a terceros en régimen de libre concurrencia, empleando o no las empresas de seguridad para la prestación de dichos servicios a personal de seguridad privada" pero argumentando ahora que "si se están prestando servicios de seguridad privada por parte de vigilantes de seguridad en modo alguno podrán emplearse este mismo personal de seguridad privada con las notas de habitualidad o regularidad precisas para ejercicio de una profesión, y no un carácter ocasional o aislado, simultáneamente en las actividades y servicios compatibles del apartado 2, ya que las funciones del vigilante de seguridad son exclusivas y excluyentes".

La Comisión Jurídica de Extremadura ${ }^{41}$ desestima el recurso pues como señala "con la previsión de los pliegos admitiendo la subcontratación tal y como está redactada, sería posible que la empresa adjudicataria acudiera a subcontratar con otras empresas las

${ }^{41}$ Resolución de la Comisión Jurídica de Extremadura nº84/2019, de 14 de noviembre. 
actividades o alguna de las actividades complementarias que, en su caso, pudiesen no considerarse compatibles".

\section{IMPUGNACIÓN DEL PRESUPUESTO BASE DE LICITACIÓN, VALOR ESTIMADO Y PRECIO PORQUE NO HAN SIDO CALCULADOS CORRECTAMENTE POR EL ÓRGANO DE CONTRATACIÓN}

La LCSP ha conferido a la determinación del precio un valor esencial, especialmente en los artículos $100^{42}$, 101 y $102^{43}$.

Es frecuente que se interpongan recursos por entender que el presupuesto base de licitación, el valor estimado y el precio no han sido calculados correctamente por el Órgano de Contratación.

La doctrina destaca al respecto tres aspectos, para determinar el precio:

$1^{\circ}$ El respeto a la normativa vigente, en especial el Convenio Colectivo estatal para empresas de seguridad ${ }^{44}$.

$2^{\text {o }}$ El principio de discrecionalidad técnica en la determinación del precio, atendiendo a los precios de mercado.

$3^{\circ}$ La concurrencia efectiva.

En relación con la impugnación de un contrato de servicios de seguridad por entender que el presupuesto base de licitación no fue calculado correctamente, el Tribunal ha señalado ${ }^{45}$ que la determinación del precio del contrato queda amparada por el principio de la discrecionalidad técnica, gozando de la presunción de acierto de que gozan las

${ }^{42}$ Artículo 100 LCSP. Presupuesto base de licitación:

“1. A los efectos de esta Ley, por presupuesto base de licitación se entenderá el límite máximo de gasto que en virtud del contrato puede comprometer el órgano de contratación, incluido el Impuesto sobre el Valor Añadido, salvo disposición en contrario.

2. En el momento de elaborarlo, los órganos de contratación cuidarán de que el presupuesto base de licitación sea adecuado a los precios del mercado. A tal efecto, el presupuesto base de licitación se desglosará indicando en el pliego de cláusulas administrativas particulares o documento regulador de la licitación los costes directos e indirectos y otros eventuales gastos calculados para su determinación. En los contratos en que el coste de los salarios de las personas empleadas para su ejecución forme parte del precio total del contrato, el presupuesto base de licitación indicará de forma desglosada y con desagregación de género y categoría profesional los costes salariales estimados a partir del convenio laboral de referencia.

3. Con carácter previo a la tramitación de un acuerdo marco o de un sistema dinámico de adquisición no será necesario que se apruebe un presupuesto base de licitación".

${ }^{43}$ Artículo 102.3 LCSP:

"Los órganos de contratación cuidarán de que el precio sea adecuado para el efectivo cumplimiento del contrato mediante la correcta estimación de su importe, atendiendo al precio general de mercado, en el momento de fijar el presupuesto base de licitación y la aplicación, en su caso, de las normas sobre ofertas con valores anormales o desproporcionados. (...)".

${ }^{44}$ Vid. Resolución del Tribunal Administrativo de Contratos Públicos de la Comunidad Autónoma de Canarias $\mathrm{n}^{\circ} 005 / 2020$, de 13 de enero.

${ }^{45}$ Resolución del TACRC n ${ }^{0} 712 / 2020$, de 19 de junio de 2020. 
declaraciones de carácter técnico mencionadas. Y añade que "en todo caso la determinación del presupuesto base de licitación se ha realizado con respeto de la normativa vigente (el Convenio colectivo estatal para las empresas de seguridad (Código de convenio n $\left.{ }^{\circ} 99004615011982\right)$ ). Y, como se ha indicado, "debemos presumir un acierto propio del que es conocedor de las cuestiones técnicas del contrato que se ha convocado en otras ocasiones, conoce suficientemente éste y los precios a que puede enfrentarse el mercado, estableciendo, dentro de sus potestades propias como tal órgano adjudicador, un precio del contrato que, desde este punto de vista, gozaría de una presunción de acierto" (resolución 237/2017, de 3 de marzo).

El Tribunal ha atendido a la existencia o no de concurrencia efectiva en diversas resoluciones, (por todas, resoluciones 660/2017, de 21 de julio, 349/2013, de 4 de septiembre, 117/2015, de 6 de febrero, o 589/2017, de 30 de junio), para determinar si el presupuesto establecido por la Administración en los pliegos puede considerarse o no ajustado a los valores de mercado.

El Tribunal concluye que "la reclamación de la recurrente debe reputarse infundada, sin que de la misma pueda inferirse racionalmente por este Tribunal que el Órgano de Contratación, al ejercer su prerrogativa natural de fijar el presupuesto base de licitación del contrato, se haya apartado de las exigencias emanadas de nuestro derecho interno y del de la Unión Europea en materia de contratación pública".

En igual sentido, el Tribunal ${ }^{46}$ considera que la mera alegación de que los costes contemplados no se adecuan a los precios de mercado no es suficiente para anular el Pliego y la licitación puesto que lo esencial en este caso es que, como señala el art. 102 de la LCSP, el precio sea el adecuado para el cumplimiento del contrato y no se han aportado evidencias de que no lo sea ni se ha desglosado tampoco en el recurso la partida que la recurrente entiende que debería figurar en el PCAP.

\section{MODIFICACIÓN SIGNIFICATIVA DE PLIEGO DE SEGURIDAD} $\mathrm{LCSP}^{47}$.

El concepto de modificación significativa viene establecido en el art. 136.2

\footnotetext{
${ }^{46}$ Resolución del Tribunal Administrativo de Contratación Pública de la Comunidad de Madrid $\mathrm{n}^{\circ}$ 116/2020, de 4 de junio de 2020.

${ }^{47}$ Artículo 136.2 LCSP:

“(...) Los órganos de contratación deberán ampliar el plazo inicial de presentación de las ofertas y solicitudes de participación, asimismo, en el caso en que se introduzcan modificaciones significativas en los pliegos de la contratación, sin perjuicio de lo señalado en los artículos 122.1 y 124.

En todo caso se considerará modificación significativa de los pliegos la que afecte a:

a) La clasificación requerida.

b) El importe y plazo del contrato.

c) Las obligaciones del adjudicatario.

d) Al cambio o variación del objeto del contrato.

La duración de la prórroga en todo caso será proporcional a la importancia de la información solicitada por el interesado".
} 
A continuación, se analizará un supuesto de modificación significativa, puesto que en fase de presentación de ofertas de la licitación el órgano de contratación modifica las condiciones establecidas en el Pliego, a través de una interpretación contraria al mismo.

Así, el Tribunal ${ }^{48}$ no puede obviar que el día 05.07.2018, un día antes de la finalización del plazo de presentación de proposiciones, el órgano de contratación ante una pregunta formulada por un licitador respecto a las condiciones de la licitación, respondió literalmente: "Buenos días, no es preciso ningún servicio de transporte de dinero". A este respeto, la cláusula 3 del PPT referida a las funciones a desarrollar en el contrato establece, entre otras, la siguiente: "-Efectuar la protección del almacenamiento, recuento, clasificación y transporte del dinero, valores y objetos valiosos".

Por lo tanto, la respuesta formulada por el órgano de contratación resulta no una mera aclaración del contenido de los pliegos, sino una verdadera modificación del contenido del PPT al suprimir por esa vía una de las funciones previstas en el contrato. Hay que precisar que esa respuesta fue objeto de publicación en la Plataforma de contratos del sector público el día 06.07.2018, último día de presentación de ofertas, y cuando ya un licitador había presentado la suya ante el órgano de contratación, lo que determina que los licitadores no pudieran formular sus proposiciones en condiciones de igualdad y abunda en las distorsiones habidas para con la correcta presentación de las ofertas por los licitadores. Así, tal actuación del órgano de contratación no fue conforme con lo previsto en el artículo 136.2 de la LCSP que establece la obligación de ampliar el plazo de presentación de proposiciones en caso de que se introduzcan modificaciones significativas en los pliegos de la contratación y especifica como tal la que afecte a los "deberes del adjudicatario".

\section{PRESENTACIÓN DE OFERTA EN LA PLATAFORMA DE CONTRATACIÓN POR LICITADOR DISTINTO DEL QUE PRESENTÓ LA DOCUMENTACIÓN DE LA OFERTA. ERROR EN LA PRESENTACIÓN ELECTRÓNICA DE LA OFERTA}

La presentación de ofertas a través de la correspondiente Plataforma de Contratación en ocasiones puede dar lugar a la exclusión del licitador, si no ha tenido la previsión de comprobar que existe coincidencia en quien presenta la oferta y la documentación de la entidad incluida en la oferta, circunstancia que puede darse en empresas pertenecientes a un mismo grupo.

En el supuesto que analizamos sucedió el hecho anteriormente indicado, y el recurrente argumentó que su exclusión en los seis lotes del procedimiento de licitación vulneraba los principios de proporcionalidad y concurrencia y que el defecto acaecido en la presentación de su oferta era una circunstancia subsanable, por lo que la mesa de contratación le debió conceder el oportuno trámite al efecto y no adoptar la decisión de exclusión.

El tribunal señala que "siendo el debate que se nos presenta, en el juicio revisor que nos corresponde en base a lo que se manifiesta, y vistas las explicaciones aportadas en

${ }^{48}$ Resolución del TACGAL n $55 / 2018$, de 8 de agosto de 2018. 
el recurso e informe del órgano de contratación y la operatividad de la Plataforma que en ellas se describe, no podemos revocar el criterio adoptado por la Diputación en base a sus alegaciones". La Diputación también alega que: "El recurso fue formulado por un licitador distinto del que presentó la oferta. Tal y como se indicó la oferta fue presentada por XX SA, y no por XX Seguridad S. A, entidades con distinta razón social y distinto NIF. En consecuencia, entiende el TACGAL que debe ser inadmitido el recurso". Añade el Tribunal que "ciertamente, esa situación podría incluso abrir el camino a la propia inadmisión del recurso presentado, puesto que la empresa efectivamente excluida no es la recurrente, sino la que presentó la oferta en el procedimiento, si bien este Tribunal consideró que a efectos de resolver el debate presentado procedía el análisis del recurso interpuesto" ${ }^{49}$.

\subsection{Impugnación de la exclusión por no alcanzar la puntuación mínima}

En primer lugar, señala el TACGAL ${ }^{50}$, es preciso hacer referencia a la consolidada doctrina de los Tribunales administrativos y de la jurisprudencia, ya argumentada por este Tribunal en varias de sus resoluciones (por todas, la Resolución del TACGAL 7/2018 o 24/2019) respecto a la discrecionalidad técnica del órgano de contratación, que goza de una presunción de acierto y validez en sus criterios técnicos, y sobre las posibilidades de revisión que le corresponden a este Tribunal, referidas a la comprobación de la debida motivación de los actos, de que no existan defectos formales, que no se utilicen criterios no previstos o arbitrarios y que no existan errores materiales en la valoración.

La Sentencia de 24 de febrero de 2016 de la Sala de lo contencioso-administrativo del Tribunal Superior de Justicia de Navarra, remarca: "Por otro lado, resulta de gran trascendencia tener igualmente en cuenta que, al tratarse de un juicio fundado en elementos de carácter exclusivamente técnico, sólo puede ser formulado por un órgano especializado, de tal modo que la revisión de la valoración realizada por el órgano previsto para resolver el concurso sólo puede hacerse cuando los errores o defectos en la valoración, primero, sean ostensibles y manifiestos, y, segundo, no exijan conocimientos técnicos" (Cf. STS 29 junio 2005). Pudiendo añadir nosotros que dichos errores "ostensibles, manifiestos y cuya valoración no exija conocimientos técnicos" han de ser, además, "relevantes".

Muy ilustrativa es la Sentencia de la Audiencia Nacional de 16 de enero de 2019 (rec.n $\left.{ }^{\circ} 1078 / 2016\right)$ : "Esta doctrina ha de completarse con las siguientes consideraciones (STS de 14 de marzo de 2018 -rec.2762/2015-), que pueden aplicarse también al ámbito de la contratación: - La primera es que, en el control jurisdiccional en la materia de que se viene hablando, el tribunal de justicia debe respetar siempre el margen de discrepancia que suele reconocerse como inevitable y legítimo en la mayoría de los sectores del saber especializado; y, en consecuencia, no puede convertirse en árbitro que dirima o decida la preferencia entre lo que sean divergencias u opiniones técnicas enfrentadas entre peritos o expertos del específico sector de conocimientos de que se trate cuando estas no rebasen los límites de ese ineludible y respetable margen de apreciación que acaba de indicarse. Así debe ser por estas razones: (i) un órgano jurisdiccional carece de conocimientos específicos para emitir un definitivo dictamen, desde una evaluación puramente técnica, que dirima lo

\footnotetext{
${ }^{49}$ Resolución del TACGAL n²52/2019, de 8 de noviembre de 2019.

${ }^{50}$ Resolución del TACGAL nº9/2020, de 16 de enero de 2020.
} 
que sean meras diferencias de criterio exteriorizadas por los expertos; (ii) la solvencia técnica y neutralidad que caracteriza a los órganos calificadores impone respetar su dictamen mientras no conste de manera inequívoca y patente que incurre en si se han producido errores materiales en la valoración de las ofertas que invaliden la adjudicación, lo que exige una reflexión previa sobre el alcance del control de la discrecionalidad técnica". En todo caso, debemos observar ahora los puntos concretos que cuestiona, todos ellos referidos a criterios a evaluar mediante juicio de valor.

Sobre esto, es de interés traer la doctrina de los Tribunales Administrativos de recursos contractuales, recogida, por ejemplo, en la reciente Resolución del Tribunal Administrativo de la Junta de Andalucía 89/201951.

La Sentencia del Tribunal General de la Unión Europea (TGUE) de 1 de febrero de 2018, asunto T-477/15, recoge que un evaluador de un contrato público debe poder tener cierto margen de maniobra para llevar a cabo su tarea y, sin modificar los criterios de adjudicación del contrato establecidos en el pliego de condiciones o el anuncio de licitación, estructurar su propio trabajo de examen y análisis de las ofertas presentadas (con cita a la Sentencia del 4 de octubre de 2012, Evropaïki Dynamiki/Comisión, asunto C-629 / $11 \mathrm{P}$, no publicado, EU: C: 2012: 617, párrafo 21).

En esta misma línea, la Resolución del Órgano Administrativo de Recursos Contractuales de Euskadi 107/2017 explica:

"En contra de lo que aduce el recurrente, no es necesario que el criterio de adjudicación especifique el método de valoración que va a seguir el evaluador (ver, en este sentido, la Resolución 131/2016 del OARC/KEAO), pues este extremo no es exigido ni por el TRLCSP ni por la jurisprudencia del TJUE la cual considera que los órganos encargados de la evaluación de los criterios de adjudicación deben disponer de cierta libertad para llevar a cabo su misión y, por ello, sin modificar los criterios de adjudicación establecidos en el pliego y anuncios ni su ponderación, estructurar su propio trabajo de examen y análisis de las ofertas presentadas. Esa libertad se justifica también por consideraciones de orden práctico; el poder adjudicador debe poder adaptar el método de valoración que aplicará para evaluar y clasificar las ofertas en función de las circunstancias de cada caso (STJUE de 14 de julio de 2016, Asunto C-6/15, "TNS Dimarso", ECLI:EU:C:2016:555, apartados 29 y 30 )".

${ }^{51}$ Cuando explica: "En este sentido, los criterios evaluables en función de juicios de valor tienen la peculiaridad de que se refieren en todo caso a cuestiones que por sus características no pueden ser evaluadas aplicando procesos que den resultados precisos predeterminables. Básicamente los elementos de juicio a considerar para establecer la puntuación que proceda asignar por tales criterios a cada proposición descansan sobre cuestiones de carácter técnico. La esencia de los criterios dependientes de un juicio de valor estriba precisamente en la existencia de una apreciación técnica personal de quien realiza el análisis, apreciación que no puede ser arbitraria, pero que tampoco puede ser matemática. Así, la admisión de los criterios de adjudicación dependientes de un juicio de valor lleva a reconocer conceptos cuya integración pueda hacerse por el órgano de contratación mediante una apreciación o valoración personal, de ahí que los conceptos empleados para su definición admitan un margen de valoración, sin que esta circunstancia pueda sobrepasar los límites de la discrecionalidad técnica". 
También cabe destacar la Sentencia del Tribunal Superior de Justicia de Asturias 273/2019, de 8 de abril de $2019^{52}$.

Por lo tanto, en base a todo esto el Tribunal acuerda que procede desestimar el recurso presentado.

\subsection{Impugnación de la exclusión de un licitador}

Cuando una oferta de un licitador no se ajusta a lo establecido en el pliego, por contradecir el pliego de prescripciones técnicas, tal circunstancia conlleva la exclusión.

El recurrente impugna su exclusión de la licitación y, de hecho, en el acta de la mesa de contratación, la Secretaria de la Mesa informa de las proposiciones presentadas indicando que los horarios ofertados por esta empresa no se ajustan a lo establecido en el pliego.

Por lo tanto, como bien consideró la mesa de contratación y recoge el informe del órgano de contratación, el motivo apreciado era causa evidente de exclusión, lo cual implica la desestimación del recurso ${ }^{53}$.

\section{PROPUESTA DE ADJUDICACIÓN DEL CONTRATO FORMULADA POR LA MESA DE CONTRATACIÓN. NO SUSCEPTIBLE DE RECURSO}

Existe una doctrina muy consolidada que ha determinado que el acuerdo de adjudicación del contrato corresponde adoptarlo al órgano de contratación, siendo este acuerdo el acto susceptible de recurso especial conforme prevé el art. 44.2 b) LCSP, no siéndolo, sin embargo, la propuesta de adjudicación que eleva la mesa de contratación.

El acto recurrido es el acuerdo adoptado por la mesa de contratación por el que se propone al órgano de contratación la adjudicación del contrato a favor de entidad diferente

\footnotetext{
${ }^{52}$ En efecto, tratándose de elementos de las ofertas valorables con arreglo a juicios de valor técnico y no mediante la aplicación de fórmulas, no basta para combatir la valoración de una parte de los criterios en los que ha obtenido menor puntuación que la adjudicataria mediante la aportación de su opinión subjetiva mediante un juicio comparativo, al objeto de acreditar que la adjudicación ha sido arbitraria, cuando estamos ante ponderaciones relativas a cuestiones de carácter técnico sobre las que la demandante no ha propuesto ningún tipo de prueba. Solo se esgrime el parecer subjetivo de la actora, pero que deviene insuficiente para acreditar que la demandada pudiera no haber aplicado a todos los concursantes los mismos criterios, que la evaluación no se haya ajustado a los Pliegos, que no se da en el presente caso, o que se haya incurrido en dolo, coacción o error manifiesto. Sobre este particular, la STS Sala $3^{a}$ de 7 julio 2011 indica que "la parte demandante, analizando cada uno de los criterios de desarrollo, viene a argumentar que dichos criterios no han sido aplicados correctamente por la Comisión; la Comisión de Valoración goza de la denominada discrecionalidad técnica en el desarrollo de su cometido de valoración, (STS 14 de julio de 2000 y 18 de julio de 2006 ), por tanto, es posible la revisión cuando se acredite la existencia de dolo, coacción, infracción de las normas reglamentarias que regulan su actuación o de las propias bases de la convocatoria, y como establece la sentencia de 18 de julio de 2006 "la revisión de esa evaluación, solo podía aceptarse, cuando, bien, no hubiera aplicado a todos los concursantes los mismos criterios, bien cuando esa evaluación no se ajustara a las bases del concurso, bien cuando existiera dolo, coacción o error manifiesto"".

${ }^{53}$ Resolución del TACGAL n²50/2019, de 8 de noviembre de 2019.
} 
a la recurrente ${ }^{54}$, pues esta empresa estaba incursa en oferta anormalmente baja, que se consideró no justificada y por ello se propuso por la mesa de contratación el rechazo de la justificación y exclusión de su oferta.

Es preciso traer a colación la doctrina dictada sobre esta cuestión por el TACRC, destacando entre otras, la reciente Resolución $n^{\circ}$ 1116/20, (recurso $n^{\circ}$ 938/2020 Illes Balears 81/2020), o la que menciona este, la resolución $\mathrm{n}^{\circ}$ 614/2020, de 21 de mayo, (recurso no 315/2020 C.A. Illes Balears 21/2020): "En efecto, nos encontramos ante un acto de trámite "no cualificado", en el que no se dan los requisitos que exige el artículo 44.2.b) de la LCSP, conforme al cual pueden ser objeto del recurso los actos de trámite adoptados en el procedimiento de adjudicación "siempre que estos decidan directa o indirectamente sobre la adjudicación, determinan la imposibilidad de continuar el procedimiento o produzcan perjuicio irreparable a derechos o intereses legítimos", considerándose que concurren las anteriores circunstancias en los "actos de la mesa o del órgano de contratación por los que se acuerde la admisión o inadmisión de candidatos o licitadores, o la admisión o exclusión de ofertas, incluidas las ofertas que sean excluidas por resultar anormalmente bajas como consecuencia de la aplicación del artículo 149 de la LCSP”.

Así, según el TACRC viene manteniendo de manera constante - por todas, Resolución 131/2020, dictada en un supuesto muy similar al que nos ocupa, y que cita Resoluciones anteriores (Resoluciones 517/2019, 552/2019, 1369/2019 ...) —, "el acto de la Mesa por el cual se propone la adjudicación del contrato en favor de determinada empresa al Órgano de contratación —o bien este mismo acto conteniendo a su vez la propuesta de exclusión de determinado licitador-, no es susceptible de impugnación conforme al artículo 44.2.b) de la LCSP, por tratarse de un "acto de trámite no cualificado, no resolutorio, pues el órgano de contratación podría separarse de la propuesta", siendo así que, si la exclusión y la adjudicación se resuelven finalmente por el Órgano de contratación según lo propuesto por la Mesa de contratación, se podrá interponer el recurso especial contra dicho acuerdo".

Debe tenerse en cuenta especialmente que el artículo 149 de la LCSP, después de explicar en el apartado $4^{\circ}$ cómo debe actuar la Mesa de contratación (o, en su defecto - es decir, en aquellos casos en que no se constituye Mesa de contratación en una licitación-el Órgano de contratación) cuando se identifica en la licitación una o varias ofertas incursas en presunción de anormalidad - formulación de requerimiento al licitador en cuestión para justificación de la viabilidad de la oferta, y solicitud de asesoramiento técnico al servicio correspondiente-, en su apartado $6^{\circ}$ ordena a la Mesa de contratación (en su defecto, al Órgano de contratación) la evaluación de la información y documentación aportada por el licitador y, después de efectuar el análisis oportuno, la elevación "de forma motivada" al Órgano de contratación de la "correspondiente propuesta de aceptación o rechazo" [de la oferta incursa en presunción de anormalidad], atribuyéndose expresamente al Órgano de contratación, a la vista de la justificación efectuada por el licitador y del informe técnico evacuado al efecto, la decisión de excluir a la empresa en cuestión si considera que la oferta no puede ser cumplida, y acordar la adjudicación en favor de la siguiente mejor oferta en el orden de clasificación ("[...Si el órgano de contratación, considerando la justificación

\footnotetext{
${ }^{54}$ Resolución del TACRC n ${ }^{\circ} 1332 / 2020$, de 10 de diciembre de 2020.
} 
efectuada por el licitador y los informes mencionados en el apartado cuatro, estimase que la información recabada no explica satisfactoriamente el bajo nivel de los precios o costes propuestos por el licitador y que, por lo tanto, la oferta no puede ser cumplida como consecuencia de la inclusión de valores anormales, la excluirá de la clasificación y acordará la adjudicación a favor de la mejor oferta, de acuerdo con el orden en que hayan sido clasificadas conforme a lo señalado en el apartado 1 del artículo 150 [...])".

Por tanto, es claro que, específicamente en el caso de la justificación de ofertas anormalmente bajas regulado en el artículo 149 de la LCSP, la Mesa de contratación no tiene potestad decisoria acerca de la exclusión de la empresa incursa en presunción de anormalidad — como tampoco la tiene acerca de la adjudicación del contrato-, sino que a dicho órgano de asistencia únicamente corresponde proponer al Órgano de contratación la exclusión de la empresa cuando considere motivadamente que ésta no ha justificado debidamente la viabilidad de su proposición — así como la adjudicación del contrato a la mejor oferta, excluida la oferta "anormal"-, siendo el Órgano de contratación, que no está vinculado por la propuesta de la Mesa de contratación (en efecto, puede separarse de su criterio, si así lo motiva debidamente) el competente para adoptar dicha decisión.

En consecuencia, la actuación impugnada, por tratarse, de un acto de trámite no cualificado, no resolutorio (no decide sobre la adjudicación - tampoco sobre la exclusión de la licitadora que no ha justificado la viabilidad de su oferta, al corresponder la decisión al Órgano de contratación-, no determina la imposibilidad de continuar el procedimiento, ni produce indefensión o perjuicio irreparable a derechos o intereses legítimos), no es susceptible de ser impugnado autónomamente a través del recurso especial en materia de contratación".

Por lo tanto, a la vista de lo expuesto procede acordar la inadmisión del recurso de conformidad con lo previsto en el art. $55 \mathrm{LCSP}^{55}$, siendo plenamente aplicables los razonamientos anteriores al presente caso, y procede en consecuencia y sin necesidad de entrar en el fondo de la cuestión, inadmitir el presente recurso, al haberse interpuesto contra un acto no recurrible.

\section{IMPUGNACIÓN DE LA ADJUDICACIÓN. DISCRECIONALIDAD TÉCNICA}

La Resolución del TACRC n 41/2020 de 16 de enero de 2020, cita la Resolución 189/2012 que señalaba que "la valoración de las ofertas de los licitadores en aquellos aspectos dependientes de juicios de valor por parte de la Mesa de contratación, constituye una manifestación particular de la denominada "discrecionalidad técnica" de la Administración, debiendo aplicarse la doctrina jurisprudencial elaborada, con carácter general, en relación con la posibilidad de revisión jurisdiccional de los actos administrativos dictados en ejercicio de las potestades discrecionales y, en particular, en

\footnotetext{
${ }^{55}$ Que señala que:

"El órgano encargado de resolver el recurso, tras la reclamación y examen del expediente administrativo, podrá declarar su inadmisión cuando constare de modo inequívoco y manifiesto cualquiera de los siguientes supuestos: (...)

c) Haberse interpuesto el recurso contra actos no susceptibles de impugnación de conformidad con lo dispuesto en el artículo 44".
} 
relación con la actuación de las Mesas de contratación al valorar criterios subjetivos o dependientes de juicios de valor".

Por su parte, cita la resolución 159/2012, que señalaba que "sólo en aquellos casos en que la valoración deriva del error, la arbitrariedad o el defecto procedimental caber entrar, no tanto en su revisión, cuanto en su anulación — seguida de una orden de práctica de una nueva valoración de conformidad con los términos de la resolución que la acuerde, a lo que se añade que, para apreciar la posible existencia de error en la valoración no se trata de realizar "un análisis profundo de las argumentaciones técnicas aducidas por las partes sino más exactamente y tal como la jurisprudencia ha puesto de manifiesto, de valorar si en la aplicación del criterio de adjudicación se ha producido un error material o de hecho que resulte patente de tal forma que pueda ser apreciado sin necesidad de efectuar razonamientos complejos" (Resolución de este Tribunal núm. 93/2012)"56.

Conviene recordar también la jurisprudencia, tantas veces referida por las resoluciones del TACRC, contenida en la Sentencia del TJUE de 24 de noviembre de 2008, Asunto Alexandroupulis, según la cual: "una entidad adjudicadora, en su competencia de valoración de ofertas en un procedimiento de licitación, no puede fijar a posteriori coeficientes de ponderación, ni aplicar reglas de ponderación o subcriterios relativos a los criterios de adjudicación establecidos en el pliego de condiciones o en el anuncio de licitación, sin que se hayan puesto previamente en conocimiento de los licitadores" 57.

En el supuesto que es objeto de examen, la pretensión del recurrente pasa por remover la valoración realizada por los servicios técnicos del órgano de contratación y asumida por la mesa de contratación, circunstancia que, como ha quedado transcrito, solo puede producirse en situaciones muy concretas, a saber, supuestos de ausencia de motivación, error manifiesto o $\operatorname{arbitrariedad}^{58}$.

El recurrente no ha justificado de forma clara que se haya producido ninguno de estos supuestos, y es por ello que debemos adelantar ya la desestimación del recurso. La mercantil se limita a comparar la valoración que ha recibido su oferta respecto a las ofertas de las demás, y a discrepar de la forma de valoración. Esa discrepancia es legítima, si bien, no es jurídicamente suficiente para que este Tribunal suplante la valoración técnica realizada por la Administración y que goza de la expresada discrecionalidad técnica ${ }^{59}$.

56 En relación con esta cuestión, es de interés la Resolución del Tribunal Administrativo de Contratación Pública de la Comunidad de Madrid n²99/2021 de 1 de julio.

${ }^{57}$ Añade el TACRC lo siguiente:

"Puede también invocarse la Resolución 368/2016, de 13 de mayo de 2016, en la cual se dijo: "[...] en lo concerniente al informe técnico de valoración de los criterios evaluables en función de juicios de valor, es que estos tienen la peculiaridad de que se refieren, en todo caso, a cuestiones que por sus características no pueden ser evaluadas aplicando procesos que den resultados precisos predeterminables. Por el contrario, aun cuando se valoren en términos absolutamente objetivos no es posible prever de antemano con certeza cuál será el resultado de la valoración. Básicamente los elementos de juicio a considerar para establecer la puntuación que procede asignar por tales criterios a cada proposición descansan sobre cuestiones de carácter técnico".

${ }^{58}$ Resolución del TACRC nº41/2020, de 16 de enero de 2020.

59 Vid. Acuerdo del Tribunal Administrativo de Contratos Públicos de Aragón 121/2019, de 13 de septiembre de 2019. 
Como señala el TACGAL 60 "debemos concluir que las cuestiones concretas en las que entra el recurso manifestando que merecía una mejor valoración, estarían dentro de la discrecionalidad técnica que corresponde al órgano de contratación, sin que se aporten elementos que puedan hacer entender que se excedió de la misma, que se incurrió en arbitrariedad u otra institución invalidante a efectos de la dimensión revisora a la que puede llegar este Tribunal, siendo las discrepancias en la evaluación expuestas por el recurrente fruto de su propio y legítimo juicio de valor, que no puede sustituir de por sí, al razonado por el órgano de contratación en el procedimiento de evaluación de las ofertas".

\subsection{Impugnación de adjudicación. Precio totalizado y no individualizado}

Es cierto que en una interpretación excesivamente rígida del pliego pueden apreciarse algunas imprecisiones de tipo formal, pero las mismas en ningún caso afectarían a la oferta propiamente dicha y, en todo caso, serían susceptibles de subsanación, no procediendo por tanto en ningún caso la exclusión de las ofertas.

En la Resolución del TACRC n ${ }^{\circ}$ 968/2020, de 11 de septiembre de 2020, el precio de las horas nocturnas, festivas y nocturnas festivas se indica totalizado y no individualizado por horas; no obstante, la información individualizada puede obtenerse si se divide el precio total especificado entre el número de horas que integran la oferta.

El Tribunal adopta un criterio antiformalista, al afirmar "la procedencia de la admisión de la anterior oferta, única solución respetuosa con el principio anti formalista y la protección de la concurrencia".

\subsection{Impugnación de adjudicación. Alegación de supuesta información privilegiada}

El Pliego que rigió la contratación de los servicios de seguridad establecía que los licitadores debían presentar un estudio de los edificios y sistemas de seguridad, que sería objeto de valoración. Una empresa recurrió la adjudicación alegando "la vulneración de los principios de igualdad de trato y concurrencia, por disponer la adjudicataria en su condición de actual adjudicataria, de información privilegiada que le ha favorecido al redactar su oferta".

Señala la Comisión Jurídica de Extremadura" que "no puede resultar atendible, pues carece de base legal y supondría un trato discriminatorio". Añade que "así como manifiesta el Tribunal Administrativo Central de Recursos Contractuales en la Resolución $562 / 2018$ de 8 de junio, “(...) no implica que exista trato o información privilegiada, sino una situación vinculada a la normal ejecución de un contrato en vigor, y consustancial a su condición de adjudicataria. (...) Es inevitable que la empresa adjudicataria adquiera cierta experiencia y conocimientos en el normal desenvolvimiento del contrato, sin que ello constituya "información privilegiada" contraria a los principios del artículo 139 del TRLCSP, ni sea, per se, una circunstancia determinante de la adjudicación, como lo

\footnotetext{
${ }^{60}$ Resolución del TACGAL n ${ }^{\circ} 128 / 2018$, de 17 de diciembre de 2018.

${ }^{61}$ Comisión Jurídica de Extremadura, Resolución n ${ }^{\circ} 59 / 2019$, de 25 de julio.
} 
demuestra el hecho de que los adjudicatarios de los contratos públicos cambien con frecuencia de una licitación a otra".

A mayor abundamiento — señala la Comisión asesora- el propio pliego establece la posibilidad de concretar visita a los locales e instalaciones de la Universidad con el objeto de poder preparar el estudio de los edificios y su sistema de seguridad, con lo que los pliegos ponen a disposición de todos los licitadores los medios necesarios para poder formular correctamente sus ofertas; opción que no utilizó la recurrente y además en su oferta, según consta en el expediente, "no presenta estudio sobre los edificios y sistemas de seguridad".

Entiendo que es relevante esta Resolución, pues deslinda los límites o fronteras entre la información privilegiada y la información que adquiere una empresa que ha prestado un servicio con anterioridad, pues entendemos que cuando todos los licitadores han podido acceder a la información no se produce la información privilegiada que pudiera afectar a los principios de igualdad y concurrencia.

En igual sentido se pronuncia la Resolución del Tribunal Administrativo de Contratación Pública de la Comunidad de Madrid nº102/2019, de 12 de marzo de $2019^{62}$.

\subsection{Impugnación de adjudicación. Alegación del licitador recurrente sobre especificación del tiempo de respuesta}

La Administración convocó un procedimiento abierto para la adjudicación del contrato de Servicio de Seguridad y Vigilancia de varios inmuebles de una Consejería. Se valoraba el tiempo de respuesta en caso de aviso de avería, incidencia o demanda de información por la Administración en la reparación de un elemento de seguridad y protección $^{63}$.

${ }^{62}$ Que invoca su Resolución 66/2016, de 13 de abril:

"Sin embargo no es menos cierto que en el entorno de mercado de que se trate, no cabe desconocer el derecho de las empresas que están realizando las prestaciones concretas contratadas a intentar obtener legalmente una nueva licitación. En tales casos por la propia lógica y dinámica empresarial, siendo el servicio a prestar el mismo, es normal que tales empresas tengan conocimientos, planes de trabajo e incluso infraestructuras que evidentemente facilitan la realización por su parte de una oferta viable y competitiva. De manera que no cabe desconocer esta circunstancia puesto que lo contrario supondría una discriminación para tales empresas, al no permitirse, de llevar al extremo la interpretación de la prohibición descrita, participar en nuevas licitaciones a las anteriores adjudicatarias de los contratos especialmente de servicio".

${ }^{63}$ El PCAP establece como criterio de adjudicación automático el siguiente:

"TIEMPO MÁXIMO DE RESPUESTA. Hasta 10 puntos.

Se puntuará el tiempo máximo de respuesta al que se compromete el licitador en caso de aviso de avería, incidencia o demanda de información por la Administración en la reparación de un elemento de seguridad y protección.

Se otorgará la máxima puntuación a la oferta con el plazo más reducido, debiendo ser inferior en cualquier caso al establecido en los pliegos (15 días), plazo que deberá ofertarse indicado en días, y proporcionalmente al resto, estableciéndose un nivel de saciedad de 5 días.

$\mathrm{P}=$ "X" puntos x plazo mínimo/ plazo oferta (regla de proporcionalidad inversa)". 
Existía una discordancia entre lo establecido por el cuadro resumen del PCAP, y el contenido del modelo de proposición, ya que uno exige que en el tiempo de respuesta se consigne el plazo ofertado en días, y el otro, en horas.

Esto provocó cierta confusión en la empresa recurrente, — según alegó- ya que, para ofertar el tiempo máximo de respuesta, y atendido el nivel de saciedad, consigna en la proposición la cifra de 0 horas.

Y, sólo cuando no resulta ser el adjudicatario la recurrente expresa que lo que ofertó es que no va a tardar más de 5 días en dar respuesta y que su oferta se ha de interpretar en el sentido de que se trata del mismo plazo de respuesta que ofertan el resto de los licitadores.

Al respecto se ha de señalar que es significativo que los otros dos licitadores rellenaran sus ofertas de la siguiente manera, dato que desconoce la recurrente y presupone el sentido de las ofertas de los demás licitadores:

YY: Tiempo máximo de respuesta. 5 días

ZZ: Tiempo máximo de respuesta. 120 horas (5 días)

Ambos licitadores entendieron que el plazo debe consignarse en días, e incluso uno de ellos lo pone en días y horas.

Los días se transforman en horas y viceversa, por eso mismo pudo la recurrente expresar su plazo máximo de respuesta en horas (120) o en días según determina el criterio o de las dos formas, pero no lo hizo y se limitó a ofertar 0 horas. Con este dato la mesa no puede entender, como pretende hacer ver ahora la recurrente, que lo que estaba ofreciendo era un tiempo máximo de respuesta de 5 días, porque no es eso lo que dice en su oferta.

La labor de la Mesa no consiste en interpretar las ofertas ni la intención de lo que la recurrente quiso decir. La Mesa constata lo que se transcribe en la oferta, esto es, en el caso de la recurrente, 0 horas como tiempo máximo de respuesta, y por ello, le otorga 0 puntos. La Mesa no interpreta tampoco las ofertas de los demás licitadores, como pretender hacer ver el recurrente, sino que se limita a transcribir las mismas y otorgarles la puntuación correspondiente.

Si bien, a juicio de la Comisión Jurídica de Extremadura ${ }^{64}$, es reprochable el uso de los llamados "umbrales de saciedad", práctica que consiste en fijar un porcentaje o tope máximo de baja a partir del cual el licitador ya no podrá obtener mayor puntuación, sin una mínima explicación que lo justifique, lo cierto es que dicho criterio no ha sido recurrido ni el motivo de impugnación se centra en esta circunstancia.

En su Resolución 65/2019, añade que: "Dicho cuanto antecede, que conduciría a la desestimación del motivo de impugnación alegado, queda por determinar si el error cometido sería susceptible de subsanación; y de nuevo debemos responder en sentido

${ }^{64}$ Comisión Jurídica de Extremadura, Resolución nº5/2019, de 21 de agosto. 
negativo pues, tal y como ya se ha expuesto, no estamos ante un mero error material que pudiese resolverse mediante una simple operación aritmética, sino que es preciso acudir a la intención manifestada por la recurrente, primero mediante escrito de 3 de mayo de 2019, tras conocer la valoración de su oferta, y segundo, mediante la interposición del recurso que ahora se resuelve, y entender que donde pone un $\mathrm{n}^{\mathrm{o}}$ de horas en realidad se quería poner otro, con lo que evidentemente supondría la modificación de los términos en los que fue realizada aquella. Es criterio general adoptado por los distintos órganos de resolución de recursos contractuales que no cabe ninguna aclaración o subsanación de la oferta cuando la presentada por la licitadora es clara y no presenta dudas o defectos que requieran aclaración, pues ello supondría posibilitar una modificación de la oferta presentada, modificación no permitida en materia de contratación pública. Por el contrario, se admitirá su subsanación cuando se cometa por el licitador un mero error de cálculo o aritmético, siempre obviamente sin alterar el sentido de la oferta ya presentada.

Pues bien en el caso que nos ocupa es evidente que la proposición de la recurrente ofrecía " 0 " horas, sin que pueda considerarse que nos encontremos ante un error material que pueda deducirse del contexto, ni siquiera por la expresión introducida en el modelo, que no parece reflejar la intención de la licitadora sino una remisión al contenido del propio PCAP" $"$.

\subsection{Impugnación valoración sin justificación}

El recurrente pretende sustituir el juicio del poder adjudicador por el suyo propio cuando alega sin prueba alguna que la puntuación otorgada es discriminatoria solo por el hecho de que el sistema ofrecido por la adjudicataria se encuentra disponible en ETS. Esta pretensión no es aceptable, pues el informante señala, de la misma forma, que el sistema propuesto por la recurrente se está utilizando en RENFE y ADIF, sin que de esas meras descripciones de donde se están utilizando ambos sistemas pueda derivarse un trato de favor en beneficio de la adjudicataria. Por otro lado, "D" no acredita ni justifica por qué determinados aspectos de su oferta deberían ser merecedores de una mayor puntuación o por qué la oferta de "A" debería obtener menos puntos, más allá de mostrar su disconformidad con las puntuaciones otorgadas por el informe técnico. Además, el informe técnico está dotado de una presunción de veracidad por la cualificación técnica de quien lo

${ }^{65}$ En este punto, se trae a colación el pronunciamiento de la Resolución 11/2015, de 29 de enero de 2015, del Titular del Órgano Administrativo de Recursos Contractuales de la Comunidad Autónoma de Euskadi: "no nos encontramos ante un error material; los errores materiales se pueden deducir del contexto en el que se insertan (error aritmético en el cálculo del importe de un porcentaje cuando la cantidad base y el tipo son inequívocamente correctos, p.ej.), por lo que el poder adjudicador puede reinterpretar la oferta a la vista de este contexto y averiguar cuál era la verdadera voluntad del licitador. No es ese el caso que nos ocupa: no hay fundamento alguno en la documentación de la proposición que haga pensar que la voluntad efectivamente expresada (...) fuera distinta de la verdadera intención de la empresa. Además, aunque existiera tal intención verdadera pero no expresada, el poder adjudicador no tendría modo alguno de aprehenderla sin que la manifieste "ex novo" el licitador excluido; (...)". Y añade "cualquier "subsanación" no sería sino la emisión por la empresa de una nueva oferta, lo que es inadmisible en el procedimiento abierto, pues sería tanto como permitir una negociación del contrato, legalmente prohibida (artículo 157 TRLCSP), así como una actuación contraria al principio de igualdad de trato de todos los licitadores, como acertadamente señala el informe de EJIE (ver, por ejemplo, en este sentido, la sentencia del Tribunal de Justicia de la Unión Europea de 29 de marzo de 2012, asunto C-599/10)". 
emite $y$, frente a ello, el recurrente no ha probado que sea manifiestamente erróneo o contenga infracción del principio de igualdad entre los licitadores ${ }^{66}$.

\subsection{Impugnación de valoración de medios diferentes a los exigidos en el PPT}

El comité de expertos valora como criterio de adjudicación "medios materiales", medios diferentes a los establecidos en el PPT, según un licitador que lo recurre alegando que:

a) La valoración de la oferta de la adjudicataria se ha realizado con apreciaciones que no estaban parametrizadas de antemano en el pliego o con cuestiones que no mejoran en nada la ejecución del contrato.

b) La ponderación realizada a la oferta de la recurrente en los criterios sujetos a juicio de valor no se corresponde con la realidad.

c) Se solicita que se declare nula la adjudicación y se retrotraigan las actuaciones para una nueva valoración.

El examen de si el poder adjudicador ha traspasado los límites de la potestad discrecional que le asiste en la evaluación del criterio secundario Medios materiales y humanos debe partir del aspecto de la oferta que valora tal criterio para lo cual se habrá de acudir a las obligaciones demandadas al contratista en el PPT, que es el documento que contiene los términos en los que el poder adjudicador desea obligarse con el adjudicatario, y refleja las necesidades que se pretenden satisfacer mediante la celebración del contrato, representa el nivel mínimo de rendimiento de las prestaciones contractuales que, de acuerdo con el interés público, desea obtener el poder adjudicador y deben cumplir todas las ofertas (ver, la Resolución 72/2018) ${ }^{67}$.

Como señala el Tribunal ${ }^{68}$ "el criterio de adjudicación secundario "Medios materiales" no puede valorar la oferta de medios diferentes a los exigidos en el PPT, como la utilización de sistemas de análisis (Mosler, cuantitativo mixto ...), ya que la mencionada cláusula del PPT no exige que se aporten sistemas de análisis de riesgos. De hecho, el poder adjudicador, consciente de que esta oferta no tiene un encaje en un criterio de adjudicación concreto, reconoce en su informe de contestación al recurso que dichos sistemas han sido valorados en este subcriterio por ser donde mejor encajan”. Por eso estima el recurso.

\subsection{Impugnación de valoración. Ausencia de arbitrariedad o discriminación}

En relación con el supuesto que se va a analizar, el recurrente alega que la parte de su oferta relativa al proyecto de sistemas de seguridad ha sido claramente infravalorada, en

${ }^{66}$ Resolución de la Titular del Órgano Administrativo de Recursos Contractuales de la Comunidad Autónoma de Euskadi 144/2020, de 30 de octubre.

${ }^{67}$ Resolución de la Titular del Órgano Administrativo de Recursos Contractuales de la Comunidad Autónoma de Euskadi 140/2020, de 23 de octubre.

${ }^{68}$ Ibidem. 
comparación con la presentada por la empresa adjudicataria. Considera que la puntuación de las ofertas ha sido "ilógica, irracional y arbitraria".

El Tribunal 69 "como ya hizo en su Resolución 19/2017, de 2 de marzo, de que en este caso el análisis del asunto sobre el que versa el recurso queda circunscrito a los aspectos formales de la valoración, tales como normas de competencia o procedimiento, la vigilancia de que en la valoración no se hayan aplicado criterios arbitrarios o discriminatorios (en consonancia con los artículos 1 y 123 de la LCSP) o que no se haya incurrido en error material (advertencia expresada, entre otras, en las Resoluciones 4, 19, $11,16,28,30 / 2012 ; 5,11,18 / 2013$; y 3, 23, 39, 43, y 81/2014)".

El Tribunal entiende que "el recurso debe desestimarse, dado que no aprecia un error patente en la aplicación de los criterios de adjudicación, ni su aplicación arbitraria o desigual $\mathrm{o}$, en definitiva, otras infracciones formales que puedan sustentar la pretensión anulatoria ejercitada, que solo parece basarse en una diferencia de criterio del licitador sobre la puntuación que considera que debe asignarse a su oferta, sin aportar mayores pruebas que lo avalen. A falta de prueba técnica independiente, esta discrepancia se resuelve a favor del criterio mantenido por la Administración, por las garantías de imparcialidad que la jurisprudencia reconoce a los informes emitidos por sus técnicos".

\subsection{Impugnación de valoración. No valorable la simple repetición del pliego}

En toda valoración de ofertas debe tomarse en consideración, de acuerdo con los criterios de adjudicación que establezca el correspondiente pliego, que la mera transcripción del PPT puede representar un cumplimiento del contrato, pero no aportar nada en cuanto a su valoración.

En la resolución que se va a comentar, el recurrente fundamenta su recurso en la indebida baremación de su oferta efectuada por el órgano de contratación en el apartado referente a la "estructura y organización del servicio", en el que alcanzó una puntuación de 1,33 sobre 14 puntos posibles. Además, cita diversas resoluciones de tribunales administrativos y jurisprudencia contrarias a la exclusión de ofertas por motivos formales.

Es lógico que la simple repetición en la oferta técnica de los requisitos mínimos fijados en el PPT no pueda ser objeto de valoración, y así lo debe entender un licitador diligente en el momento de la presentación de su oferta ${ }^{70}$.

\section{SUBROGACIÓN DE TRABAJADORES DE EMPRESAS DE SEGURIDAD}

Las cuestiones relativas a la información de la subrogación tienen una gran transcendencia en el ámbito de los contratos de servicios de seguridad, puesto que los convenios colectivos sectoriales vienen reconociendo este derecho a los trabajadores que cumplan los requisitos establecidos en el convenio.

\footnotetext{
${ }^{69}$ Resolución del Tribunal Administrativo de Recursos Contractuales de Castilla y León 86/2018, de 19 de septiembre.

${ }^{70}$ Resolución del TACGAL n ${ }^{\circ}$ 18/2018, de 4 de junio de 2018.
} 
Como antecedentes de la subrogación encontramos la Ley de Contrato de Trabajo de 21 de noviembre de $1931^{71}$, el Decreto de 26 de enero de 1944 por el que se aprueba el texto refundido del Libro I de la Ley de Contrato de Trabajo ${ }^{72}$, la Ley 8/1980, de 10 de marzo, del Estatuto de los Trabajadores (BOE n⿳0 64, de 14 de marzo de 1980) ${ }^{73}$, el Real Decreto Legislativo 1/1995, de 24 de marzo, por el que se aprueba el texto refundido de la Ley del Estatuto de los Trabajadores ${ }^{74}$, que fue modificado por la Ley 12/2001, de 9 de julio, de medidas urgentes de reforma del mercado de trabajo para el incremento del empleo y la mejora de su calidad, y en concreto el art. $44^{75}$. El Real Decreto Legislativo $2 / 2015$, de 23 de octubre, por el que se aprueba el texto refundido de la Ley del Estatuto de los Trabajadores ${ }^{76}\left(\mathrm{BOE}^{\mathrm{o}} 255\right.$, de 24 de octubre de 2015) reguló con mayor amplitud esta

\footnotetext{
${ }^{71}$ Artículo 90:

"No terminará el contrato de trabajo por cesión, traspaso o venta de la industria, a no ser que en aquél se hubiera pactado expresamente lo contrario" (Gaceta de Madrid, n³26, de 22 de noviembre de 1931).

${ }^{72}$ Artículo 79:

"No terminará el contrato de trabajo por cesión, traspaso o venta de la industria, a no ser que en aquel contrato se hubiera pactado expresamente lo contrario, quedando el nuevo empresario subrogado en los derechos y obligaciones del anterior" (BOE n55, de 24 de febrero de 1944).

73 Artículo 44. La sucesión de empresa:

"Uno. El cambio de la titularidad de la empresa, centro de trabajo o de una unidad productiva autónoma de la misma, no extinguirá por sí mismo la relación laboral, quedando el nuevo empresario subrogado en los derechos y obligaciones laborales del anterior. Cuando el cambio tenga lugar por actos ínter vivos, el cedente, y en su defecto el cesionario, está obligado a notificar dicho cambio a los representantes legales de los trabajadores de la empresa cedida, respondiendo ambos solidariamente durante tres años de las obligaciones laborales nacidas con anterioridad a la transmisión y que no hubieran sido satisfechas.

Dos. El cedente y el cesionario responderán también solidariamente de las obligaciones nacidas con posterioridad a la transmisión, cuando la cesión fuese declarada delito".

74 Artículo 44. La sucesión de empresa:

"1. El cambio de la titularidad de la empresa, centro de trabajo o de una unidad productiva autónoma de la misma, no extinguirá por sí mismo la relación laboral, quedando el nuevo empresario subrogado en los derechos y obligaciones laborales del anterior. Cuando el cambio tenga lugar por actos ínter vivos, el cedente, $\mathrm{y}$, en su defecto, el cesionario, está obligado a notificar dicho cambio a los representantes legales de los trabajadores de la empresa cedida, respondiendo ambos solidariamente durante tres años de las obligaciones laborales nacidas con anterioridad a la transmisión y que no hubieran sido satisfechas.

2. El cedente y el cesionario responderán también solidariamente de las obligaciones nacidas con posterioridad a la transmisión, cuando la cesión fuese declarada delito".

75 Este Estatuto de 1980 dio lugar a diversos informes de la Junta Consultiva de Contratación, en relación con subrogaciones en contratos de la Administración. Vid. Informe 31/1999, de 30 de junio; Informe 33/02, de 23 de octubre de 2002; Informe 50/07, de 29 de octubre de 2007; Informe 58/09, de 26 de febrero de 2010; Informe 63/11, de 17 julio de 2012.

${ }^{76}$ Artículo 44. La sucesión de empresa:

"1. El cambio de titularidad de una empresa, de un centro de trabajo o de una unidad productiva autónoma no extinguirá por sí mismo la relación laboral, quedando el nuevo empresario subrogado en los derechos y obligaciones laborales y de Seguridad Social del anterior, incluyendo los compromisos de pensiones, en los términos previstos en su normativa específica, y, en general, cuantas obligaciones en materia de protección social complementaria hubiere adquirido el cedente.

2. A los efectos de lo previsto en este artículo, se considerará que existe sucesión de empresa cuando la transmisión afecte a una entidad económica que mantenga su identidad, entendida como un conjunto de medios organizados a fin de llevar a cabo una actividad económica, esencial o accesoria.

3. Sin perjuicio de lo establecido en la legislación de Seguridad Social, el cedente y el cesionario, en las transmisiones que tengan lugar por actos inter vivos, responderán solidariamente durante tres años de las obligaciones laborales nacidas con anterioridad a la transmisión y que no hubieran sido satisfechas.
} 
cuestión. El convenio colectivo de empresas de Seguridad regula la subrogación en los artículos 14 a $18^{77}$.

\author{
A nivel de la normativa comunitaria la subrogación se regula en la Directiva \\ 2001/23/CE ${ }^{78}$ del Consejo, de 12 de marzo de 2001, sobre la aproximación de las
}

El cedente y el cesionario también responderán solidariamente de las obligaciones nacidas con posterioridad a la transmisión, cuando la cesión fuese declarada delito.

4. Salvo pacto en contrario, establecido mediante acuerdo de empresa entre el cesionario y los representantes de los trabajadores una vez consumada la sucesión, las relaciones laborales de los trabajadores afectados por la sucesión seguirán rigiéndose por el convenio colectivo que en el momento de la transmisión fuere de aplicación en la empresa, centro de trabajo o unidad productiva autónoma transferida.

Esta aplicación se mantendrá hasta la fecha de expiración del convenio colectivo de origen o hasta la entrada en vigor de otro convenio colectivo nuevo que resulte aplicable a la entidad económica transmitida.

5. Cuando la empresa, el centro de trabajo o la unidad productiva objeto de la transmisión conserve su autonomía, el cambio de titularidad del empresario no extinguirá por sí mismo el mandato de los representantes legales de los trabajadores, que seguirán ejerciendo sus funciones en los mismos términos y bajo las mismas condiciones que regían con anterioridad.

6. El cedente y el cesionario deberán informar a los representantes legales de sus trabajadores respectivos afectados por el cambio de titularidad, de los siguientes extremos:

a) Fecha prevista de la transmisión.

b) Motivos de la transmisión.

c) Consecuencias jurídicas, económicas y sociales, para los trabajadores, de la transmisión.

d) Medidas previstas respecto de los trabajadores.

7. De no haber representantes legales de los trabajadores, el cedente y el cesionario deberán facilitar la información mencionada en el apartado anterior a los trabajadores que pudieren resultar afectados por la transmisión.

8. El cedente vendrá obligado a facilitar la información mencionada en los apartados anteriores con la suficiente antelación, antes de la realización de la transmisión. El cesionario estará obligado a comunicar estas informaciones con la suficiente antelación y, en todo caso, antes de que sus trabajadores se vean afectados en sus condiciones de empleo y de trabajo por la transmisión.

En los supuestos de fusión y escisión de sociedades, el cedente y el cesionario habrán de proporcionar la indicada información, en todo caso, al tiempo de publicarse la convocatoria de las juntas generales que han de adoptar los respectivos acuerdos.

9. El cedente o el cesionario que previere adoptar, con motivo de la transmisión, medidas laborales en relación con sus trabajadores vendrá obligado a iniciar un periodo de consultas con los representantes legales de los trabajadores sobre las medidas previstas y sus consecuencias para los trabajadores. Dicho periodo de consultas habrá de celebrarse con la suficiente antelación, antes de que las medidas se lleven a efecto. Durante el periodo de consultas, las partes deberán negociar de buena fe, con vistas a la consecución de un acuerdo. Cuando las medidas previstas consistieren en traslados colectivos o en modificaciones sustanciales de las condiciones de trabajo de carácter colectivo, el procedimiento del periodo de consultas al que se refiere el párrafo anterior se ajustará a lo establecido en los artículos 40.2 y 41.4 .

10. Las obligaciones de información y consulta establecidas en este artículo se aplicarán con independencia de que la decisión relativa a la transmisión haya sido adoptada por los empresarios cedente y cesionario o por las empresas que ejerzan el control sobre ellos. Cualquier justificación de aquéllos basada en el hecho de que la empresa que tomó la decisión no les ha facilitado la información necesaria no podrá ser tomada en consideración a tal efecto".

${ }^{77}$ Resolución de 18 de noviembre de 2020, de la Dirección General de Trabajo, por la que se registra y publica el Convenio colectivo estatal de las empresas de seguridad para el año 2021 (BOE nº310, de 26 de noviembre de 2020).

${ }^{78}$ Artículo 3:

“1. Los derechos y obligaciones que resulten para el cedente de un contrato de trabajo o de una relación laboral existente en la fecha del traspaso, serán transferidos al cesionario como consecuencia de tal traspaso. Los Estados miembros podrán establecer que, después de la fecha del traspaso, el cedente y el cesionario sean 
legislaciones de los Estados miembros relativas al mantenimiento de los derechos de los trabajadores en caso de traspasos de empresas, de centros de actividad o de partes de empresas o de centros de actividad ${ }^{79}$.

A diferencia de la normativa laboral que como hemos expuesto brevemente ha regulado la materia con una jurisprudencia consolidada ${ }^{80}$, la normativa de contratos ha realizado una lenta evolución, así la LCAP (Disposición final cuarta. Información sobre obligaciones de carácter laboral) ${ }^{81}$, el Texto Refundido de la Ley de Contratos de las Administraciones Públicas, aprobado por Real Decreto Legislativo 2/2000, de 16 de junio (Disposición Final Cuarta) ${ }^{82}$. Poco a poco se fue regulando la materia, así ya se abordó en

responsables solidariamente de las obligaciones que tuvieran su origen, antes de la fecha del traspaso, en un contrato de trabajo o en una relación laboral existentes en la fecha del traspaso.

2. Los Estados miembros podrán adoptar las medidas necesarias para garantizar que el cedente notifique al cesionario todos los derechos y obligaciones que, en virtud del presente artículo, se transferirán al cesionario, en la medida en que en el momento del traspaso el cedente tenga o debiera haber tenido conocimiento de dichos derechos y obligaciones. En caso de que el cedente no notifique al cesionario alguno de estos derechos u obligaciones, ello no afectará al traspaso del derecho o de la obligación ni a los derechos de los trabajadores frente al cesionario o al cedente en relación con dicho derecho u obligación. 3. Después del traspaso, el cesionario mantendrá las condiciones de trabajo pactadas mediante convenio colectivo, en los mismos términos aplicables al cedente, hasta la fecha de extinción o de expiración del convenio colectivo, o de la entrada en vigor o de aplicación de otro convenio colectivo. Los Estados miembros podrán limitar el período de mantenimiento de las condiciones de trabajo, pero éste no podrá ser inferior a un año. (...)”.

Artículo 4:

"1. El traspaso de una empresa, de un centro de actividad o de una parte de éstos no constituirá en sí mismo un motivo de despido para el cedente o para el cesionario. Esta disposición no impedirá los despidos que puedan producirse por razones económicas, técnicas o de organización que impliquen cambios en el plano del empleo.

Los Estados miembros podrán establecer que no se aplique el párrafo primero a determinadas categorías concretas de trabajadores que no estén cubiertas por la legislación o la práctica de los Estados miembros en materia de protección contra el despido.

2. Si el contrato de trabajo o la relación laboral se rescinde como consecuencia de que el traspaso ocasiona una modificación substancial de las condiciones de trabajo en perjuicio del trabajador, la rescisión del contrato de trabajo o de la relación laboral se considerará imputable al empresario".

${ }^{79}$ Con anterioridad existían las siguientes Directivas: La Directiva 77/187 CEE del Consejo, de 14 de febrero de 1977, sobre la aproximación de las legislaciones de los Estados Miembros relativas al mantenimiento de los derechos de los trabajadores en caso de traspasos de empresas, de centros de actividad o de partes de centros de actividad y la Directiva 98/50 CE del Consejo, de 29 de junio de 1998, por la que se modifica la Directiva 77/187/CEE sobre la aproximación de las legislaciones de los Estados miembros relativas al mantenimiento de los derechos de los trabajadores en caso de traspaso de empresas, de centros de actividad o de partes de centros de actividad.

${ }^{80}$ Vid. Sentencia del Tribunal de Justicia de la UE (Sala Décima), de 11 de julio de 2018 (SOMOZA HERMO); STS 873/2018, de 27 de septiembre de 2018; STS 991/2019; Sentencia del Tribunal de Justicia de la UE (Sala Octava) de 13 de junio de 2019, asunto C-317/18, Caso CORREIA MOREIRA.

${ }^{81}$ Disposición final cuarta. Información sobre obligaciones de carácter laboral. Ley 13/1995, de 18 de mayo, de Contratos de las Administraciones Públicas:

"Los órganos de contratación podrán señalar en los pliegos de cláusulas administrativas particulares la autoridad o autoridades de las que los licitadores puedan obtener informaciones sobre las obligaciones relativas a las disposiciones sobre protección y condiciones de trabajo vigentes en el territorio en el que vayan a ejecutarse las obras o prestarse los servicios, en cuyo supuesto solicitarán a los licitadores que manifiesten si han tenido en cuenta en sus ofertas tales obligaciones".

82 Disposición final cuarta. Información sobre obligaciones de carácter laboral. Real Decreto Legislativo 2/2000, de 16 de junio, por el que se aprueba el texto refundido de la Ley de Contratos de las Administraciones Públicas: 
la Ley 30/2007, de Contratos del Sector Público ${ }^{83}$, en el Texto Refundido de la Ley de Contratos del Sector Público (TRLCAP) ${ }^{84}$ y en la vigente Ley 9/2017, de Contratos del Sector Público (LCSP), en su art. 130.

El art. $130 \mathrm{LCSP}^{85}$ ha representado un avance en lo que respecta a la regulación de la subrogación en la contratación. Ha dado lugar a diversos informes de la Junta Consultiva de Contratación ${ }^{86}$ y a diversas resoluciones del TACRC ${ }^{87}$.

"Los órganos de contratación podrán señalar en los pliegos de cláusulas administrativas particulares la autoridad o autoridades de las que los licitadores puedan obtener informaciones sobre las obligaciones relativas a las disposiciones sobre protección y condiciones de trabajo vigentes en el territorio en el que vayan a ejecutarse las obras o prestarse los servicios, en cuyo supuesto solicitarán a los licitadores que manifiesten si han tenido en cuenta en sus ofertas tales obligaciones".

${ }^{83}$ Artículo 104. Información sobre las condiciones de subrogación en contratos de trabajo. Ley 30/2007, de 30 de octubre, de Contratos del Sector Público:

"En aquellos contratos que impongan al adjudicatario la obligación de subrogarse como empleador en determinadas relaciones laborales, el órgano de contratación deberá facilitar a los licitadores, en el propio pliego o en la documentación complementaria, la información sobre las condiciones de los contratos de los trabajadores a los que afecte la subrogación que resulte necesaria para permitir la evaluación de los costes laborales que implicará tal medida. A estos efectos, la empresa que viniese efectuando la prestación objeto del contrato a adjudicar y que tenga la condición de empleadora de los trabajadores afectados estará obligada a proporcionar la referida información al órgano de contratación, a requerimiento de éste".

${ }^{84}$ Artículo 120. Información sobre las condiciones de subrogación en contratos de trabajo. Real Decreto Legislativo 3/2011, de 14 de noviembre, por el que se aprueba el texto refundido de la Ley de Contratos del Sector Público:

"En aquellos contratos que impongan al adjudicatario la obligación de subrogarse como empleador en determinadas relaciones laborales, el órgano de contratación deberá facilitar a los licitadores, en el propio pliego o en la documentación complementaria, la información sobre las condiciones de los contratos de los trabajadores a los que afecte la subrogación que resulte necesaria para permitir la evaluación de los costes laborales que implicará tal medida. A estos efectos, la empresa que viniese efectuando la prestación objeto del contrato a adjudicar y que tenga la condición de empleadora de los trabajadores afectados estará obligada a proporcionar la referida información al órgano de contratación, a requerimiento de éste".

${ }^{85}$ Artículo 130 LCSP. Información sobre las condiciones de subrogación en contratos de trabajo.

"1. Cuando una norma legal un convenio colectivo o un acuerdo de negociación colectiva de eficacia general, imponga al adjudicatario la obligación de subrogarse como empleador en determinadas relaciones laborales, los servicios dependientes del órgano de contratación deberán facilitar a los licitadores, en el propio pliego, la información sobre las condiciones de los contratos de los trabajadores a los que afecte la subrogación que resulte necesaria para permitir una exacta evaluación de los costes laborales que implicará tal medida, debiendo hacer constar igualmente que tal información se facilita en cumplimiento de lo previsto en el presente artículo.

A estos efectos, la empresa que viniese efectuando la prestación objeto del contrato a adjudicar y que tenga la condición de empleadora de los trabajadores afectados estará obligada a proporcionar la referida información al órgano de contratación, a requerimiento de este. Como parte de esta información en todo caso se deberán aportar los listados del personal objeto de subrogación, indicándose: el convenio colectivo de aplicación y los detalles de categoría, tipo de contrato, jornada, fecha de antigüedad, vencimiento del contrato, salario bruto anual de cada trabajador, así como todos los pactos en vigor aplicables a los trabajadores a los que afecte la subrogación. La Administración comunicará al nuevo empresario la información que le hubiere sido facilitada por el anterior contratista.

2. Lo dispuesto en este artículo respecto de la subrogación de trabajadores resultará igualmente de aplicación a los socios trabajadores de las cooperativas cuando estos estuvieran adscritos al servicio o actividad objeto de la subrogación.

Cuando la empresa que viniese efectuando la prestación objeto del contrato a adjudicar fuese un Centro Especial de Empleo, la empresa que resulte adjudicataria tendrá la obligación de subrogarse como empleador 
A) Impugnación de la información de subrogación. Deber de información del art. 130 de la LCSP

El alcance de la obligación que el art. 130 de la LCSP impone al órgano de contratación presenta una naturaleza formal que como indica la Junta Consultiva de Contratación Pública del Estado, en su informe 61/2019:

"Únicamente le obliga a requerir al contratista anterior una información determinada, así como, una vez proporcionada tal información, a facilitarla a los licitadores, sin que el precepto imponga — ni del mismo se deduzca - ninguna obligación para el órgano de contratación de comprobar la veracidad material o intrínseca de aquella información".

Del mismo modo, al órgano de contratación, de conformidad con el art. 130 de la LCSP le incumbe requerir la información y una vez remitida por el órgano de contratación, únicamente deberá verificar si los datos remitidos, en términos formales, son los exigidos

de todas las personas con discapacidad que vinieran desarrollando su actividad en la ejecución del referido contrato.

3. En caso de que una Administración Pública decida prestar directamente un servicio que hasta la fecha venía siendo prestado por un operador económico, vendrá obligada a la subrogación del personal que lo prestaba si así lo establece una norma legal, un convenio colectivo o un acuerdo de negociación colectiva de eficacia general.

4. El pliego de cláusulas administrativas particulares contemplará necesariamente la imposición de penalidades al contratista dentro de los límites establecidos en el artículo 192 para el supuesto de incumplimiento por el mismo de la obligación prevista en este artículo.

5. En el caso de que una vez producida la subrogación los costes laborales fueran superiores a los que se desprendieran de la información facilitada por el antiguo contratista al órgano de contratación, el contratista tendrá acción directa contra el antiguo contratista.

6. Asimismo, y sin perjuicio de la aplicación, en su caso, de lo establecido en el artículo 44 del texto refundido de la Ley del Estatuto de los Trabajadores, aprobado por Real Decreto Legislativo 2/2015, de 23 de octubre, el pliego de cláusulas administrativas particulares siempre contemplará la obligación del contratista de responder de los salarios impagados a los trabajadores afectados por subrogación, así como de las cotizaciones a la Seguridad social devengadas, aún en el supuesto de que se resuelva el contrato y aquellos sean subrogados por el nuevo contratista, sin que en ningún caso dicha obligación corresponda a este último. En este caso, la Administración, una vez acreditada la falta de pago de los citados salarios, procederá a la retención de las cantidades debidas al contratista para garantizar el pago de los citados salarios, y a la no devolución de la garantía definitiva en tanto no se acredite el abono de éstos”.

${ }^{86}$ Expediente 61/19, Materia: Interpretación del artículo 130 de la Ley 9/2017, de 8 de noviembre, de Contratos del Sector Público; Expediente 51/19, Materia: Cláusulas de subrogación; Expediente 35/19, Materia: Diversas cuestiones relacionadas con la subrogación de los trabajadores de contratos públicos anteriores; Expediente 12/19, Materia: Subrogación de trabajadores; Expediente 126/18, Materia: Información que se debe ofrecer al contratista en el caso de subrogación de trabajadores; Expediente 112/18, Materia: Coexistencia de la gestión directa e indirecta de servicios por parte de la Administración; Expediente 37/16, de 10 de diciembre de 2018, Duda sobre cláusula de prórroga automática del servicio de limpieza en tanto no comience a prestarlo un nuevo contratista, Diputación Provincial de Cádiz; Expediente 24/20, relativo a Subrogación de trabajadores.

${ }^{87}$ Resolución nº99/2020; Resolución nº80/2020; Resolución nº55/2020; Resolución nº535/2020; Resolución n²55/2020; Resolución n³96/2020; Resolución n³53/2020; Resolución n²14/2020; Resolución $n^{\circ} 1355 / 2019$; Resolución $n^{\circ} 1333 / 2019$; Resolución nº1292/2019; Resolución nº 1035/2019; Resolución n994/2019; Resolución nº65/2019; Resolución n554/2019. 
por la Ley, es decir, que la información suministrada tiene las menciones mínimas recogidas en el art. 130.5 de la LCSP. Así se pronuncia el citado Informe 61/2019 cuando señala que:

"Es importante destacar en este punto que la obligación de concretar qué información es necesaria a estos efectos recae sobre el contratista saliente puesto que, por un lado, es el único que verdaderamente conoce la situación de sus trabajadores y de su empresa, así como las eventuales circunstancias que pudieran influir en la determinación del coste salarial para el caso de una eventual subrogación, y, por otro, es a dicho contratista al que la LCSP obliga a asumir las consecuencias en el caso de que, una vez producida la subrogación, los costes laborales fueren superiores a los que se desprendieren de la información facilitada por el antiguo contratista. El órgano de contratación se puede limitar a requerir al contratista para que le remita la información necesaria, comprobando que se ha remitido con los datos legalmente establecidos que constituyen el mínimo de información exigible, o con los incluidos en el pliego".

Añade a continuación que: "Una vez delimitado el alcance de dicha obligación, y aplicando la doctrina expuesta al caso que nos ocupa, podemos advertir que tanto en la documentación que figura en el Anexo V del PCAP, como en la rectificación instada posteriormente por la empresa saliente (después de la cual se concedió nuevo plazo para presentar ofertas), toda ella firmada por la representante de aquella contratista, cumple con los requisitos de contenido mínimo de la información sobre costes salariales que el artículo 130 de la LCSP obliga a recabar al órgano de contratación.

De esta manera, si a partir de dicha información, sea por omisión o por falta de especificación de los datos, no pudieran determinarse correctamente los costes salariales, de manera que una vez producida la subrogación, éstos fueran superiores a los que se dedujeron a partir de aquella información, las consecuencias de tal incumplimiento habrán de ser asumidas por la contratista saliente de conformidad con el artículo 130.5 de la LCSP.

Todo ello sin perjuicio de que, como indica el órgano de contratación en su informe, por los licitadores pueda requerirse información adicional, bien a través de la plataforma, bien a través de cualquiera de los medios establecidos en la LCSP, sin que, como es lógico, tal requerimiento, que habrá de trasladarse al contratista saliente, altere la naturaleza de la obligación que el artículo 130 de la LCSP impone al órgano de contratación.

En conclusión, de los datos que obran en el expediente y de conformidad con lo dispuesto en este fundamento, no se aprecia infracción de la obligación contenida en el artículo 130 de la LCSP, por lo que el este motivo de impugnación ha de desestimarse" 88 .

B) Subrogación. No inclusión de la información del representante de trabajadores

\footnotetext{
${ }^{88}$ Resolución del TACRC n ${ }^{\circ} 1172 / 2020$, de 30 de octubre de 2020.
} 
La cuestión que se plantea es la trascendencia en el ámbito contractual de la omisión de la información del representante de los trabajadores, por no haberse comunicado con anterioridad a la subrogación.

La Resolución del TACRC n ${ }^{\circ}$ 1406/2020, de 30 de diciembre de 2020, resuelve esta cuestión, indicando que "el recurso no puede prosperar. La recurrente no ha aportado ninguna prueba de que hubiera comunicado con la antelación que indica, la condición de representantes de los trabajadores de algunos de los que podían tener derecho a la subrogación en su relación laboral. El único documento que aporta está firmado electrónicamente, tal y como indica el órgano de contratación, el día anterior a la conclusión del plazo de presentación de ofertas. Pero es que con independencia de que la información se hubiera aportado oportunamente, la misma era irrelevante, excepto para la propia empresa recurrente. En efecto, según la doctrina del orden jurisdiccional social, la condición de representante de los trabajadores no se conserva en un caso como el actual. Como estableció la sentencia del Tribunal Supremo de 10 de diciembre de 2013 (Rec. 635/2012), el mantenimiento del mandato depende de la subsistencia de la unidad productiva trasferida, como entidad económica autónoma, pero constituida, asimismo, como unidad electoral. De este modo, la autonomía que exige la normativa sobre transmisión de empresa para el mantenimiento del mandato representativo de los trabajadores, no se entiende en términos puramente organizativos o funcionales, sino en sentido de autonomía a efectos electorales. El mantenimiento de la representación de los trabajadores no depende de la propia transmisión, ya que la representación del personal no puede quedar afectada por un acto discrecional del empresario, sino solo por las circunstancias en que se produce. Esto determina que, en casos como el presente en los que el ámbito de representación para el que habían sido elegidos los trabajadores afectados por un traspaso, no solo era el del centro de trabajo en que prestaban sus servicios, sino que comprendía varios centros más, que no habían sido objeto de transmisión y, por tanto, seguían perteneciendo a la saliente, no se mantiene el mandato representativo [en este sentido se pronuncian las sentencias de los Tribunales Superiores de Justicia de Cataluña de 30 de mayo de 2011, (Rec. 1186/2011), y Extremadura, de 21 de enero de 2004 (Rec.830/2003), entre otras].

La condición de representantes de los trabajadores que se ha adquirido a través del proceso electoral regulado en el Título II del Estatuto de los Trabajadores se extingue cuando desaparece la base objetiva sobre la que operó la elección. Por tanto, la condición de representante de los trabajadores, en caso de cambio de empresa se perdería y, con ello el eventual crédito horario, quedando sólo las garantías de permanencia en el puesto de trabajo. No es precisa la publicación de dicha información". visitantes

C) Subrogación de trabajadores en contrato de servicios de seguridad y atención de

La resolución del TACRC $\mathrm{n}^{\circ} 1301 / 2021$, de 29 de septiembre, considera que la obligación de subrogación solo procede en los contratos de vigilantes de seguridad, de acuerdo con lo previsto en el Convenio colectivo estatal de empresas de seguridad, pero no el personal subcontratado de atención a visitantes, pues respecto a este personal no lo prevé el respectivo convenio colectivo. 


\section{INEXISTENCIA DE OFERTA ANORMALMENTE BAJA}

Las ofertas anormalmente bajas se regulan en la LCSP principalmente en el art. 149, así como en los arts. 44.2 b); 167 e); 226.4 y 336.1 c).

El recurrente impugna el acuerdo de adjudicación, pues considera que la empresa adjudicataria "infringe de forma manifiesta lo estipulado en los artículos 149 y 201 de la LCSP. Resultando con ello, que a voluntad del órgano de contratación, y de su necesidad o no de cubrir las "horas al alza" ofertadas, su oferta podría estar incursa en baja anormal, vulnerando además el cumplimiento del convenio colectivo de aplicación".

Señala el tribunal ${ }^{89}$ que "fijada con claridad en los pliegos de la licitación la regla para calcular el umbral de temeridad, de ninguna forma puede pretender el recurrente, que se presentó a la licitación y consintió el contenido de los pliegos, que una vez conocido el contenido de las ofertas esa regla establecida por igual para todos los licitadores se modifique - una vez la adjudicación no recayó a su favor- en su propio beneficio, pues supondría un quebranto de los principios de igualdad, transparencia y libre concurrencia. Además de que el cálculo indicado en el recurso, que se hace depender de una presunción de cómo se irá desarrollando la posterior ejecución contractual, carece de un mínimo engarce no solo con el contenido de los pliegos, sino con la propia configuración de un procedimiento de licitación, y resulta igualmente un cálculo artificioso pues como señala el alegante a este recurso especial "todas las ofertas presentadas, incluida la recurrente, han ofertado las mismas 6.000 horas, sin embargo, no las toma en consideración para calcular la media aritmética sino sólo para reducir la oferta de la adjudicataria, lo que resulta a todas luces incoherente", aspecto que también destaca el informe del órgano de contratación" 90.

En todo caso, cabe indicar además que esa vulneración del convenio colectivo alegada por el recurrente es negada por el órgano de contratación en su informe a este recurso, que destaca que los costes ahora presentados en el recurso para fundamentar sus estimaciones difieren sustancialmente de los entregados por el propio recurrente al órgano de contratación respecto a la información sobre las condiciones de subrogación, por ejemplo y de modo muy relevante en los gastos de kilometraje. Por último, resalta que no cabe en este momento una impugnación del contenido de los pliegos de la licitación, como parece pretender el recurrente en algunas partes de su escrito de recurso, por quien siendo licitador y no impugnando esos pliegos en el momento procesal oportuno, alega extemporáneamente esa crítica al conocer que no resulta ganador del procedimiento de licitación.

${ }^{89}$ Resolución del TACGAL nº125/2020, de 19 de agosto de 2020.

${ }^{90}$ La Resolución del TACRC 248/2020 también recoge que:

"En estos términos, no cabe exigir justificación alguna de la viabilidad de la oferta no incursa en presunción de anormalidad determinada de acuerdo con el pliego, ni, por ende, acordar su exclusión posterior. Y ello en la medida en que el artículo 149.1 LCSP sólo habilita este procedimiento para el supuesto en que exista una oferta presuntamente inviable. Es decir, no es que sólo quepa solicitar la justificación de la viabilidad "previa tramitación" del procedimiento, sino que sólo cabe acudir al propio procedimiento cuando se cumple su presupuesto de hecho, que es la presunción de anormalidad que surge de la aplicación de los parámetros del pliego". 
El Tribunal Superior de Justicia de Galicia ya advierte frente a los intentos de cuestionar las reglas de la contratación, precisamente en el momento en que ese licitador conoce que no es el adjudicatario ("es contrario a la buena fe", afirma el TSXG). Por ejemplo, en su Sentencia de 17 de noviembre de 2016 ${ }^{91}$ (rec. 4274/2015). Todo lo cual determina, en definitiva, que proceda la desestimación del recurso.

Recordemos en este sentido que la Resolución del TACRC n¹046/2021 de 2 de septiembre indicaba que "el rechazo de la oferta exige de una resolución debidamente motivada que razone por qué las justificaciones del licitador no explican satisfactoriamente el bajo nivel de precios ofertados. Por el contrario, cuando de lo que se trata es de admitir la justificación presentada por el licitador, no es necesario que se contenga una motivación exhaustiva (resolución n637/2015)", añadiendo que "como indica la resolución 457/2016, de 10 de junio de este Tribunal las alegaciones del licitador no deben "justificar exhaustivamente la oferta desproporcionada, sino de proveer de argumentos que permitan al órgano de contratación llegar a la convicción de que se puede llevar a cabo. (...)".

En relación con las ofertas de bolsas de horas, es de interés la resolución del TACRC nº 1046/2021, de 2 de septiembre, que sigue la línea de la resolución 934/2018, que señala que, "respecto del criterio de adjudicación consistente en bolsas de horas, criterio que habitualmente se utiliza como criterio cuantitativo de mejora, no puede sin embargo negarse que repercute sobre la calidad del servicio". No obstante, entendemos que no deberían recogerse en los pliegos como mejora o como criterio de adjudicación las bolsas de horas gratuitas y en todo caso debería haber un máximo de horas con un índice de saciedad y determinarse su coste en el presupuesto base de licitación.

\section{CONCLUSIONES}

Los recursos en materia de servicios de seguridad abarcan aspectos diversos, como hemos expuesto.

1. En relación con la legitimación de los sindicatos para interponer el recurso especial en materia de contratación, se aplica la doctrina de que la legitimación procesal del sindicato en el orden jurisdiccional contencioso-administrativo se ha de localizar en la noción de interés profesional o económico.

91 "La impugnación de los pliegos, que son la ley del contrato, por la licitadora o competidora (...) era posible, pero dentro del plazo establecido al efecto en el artículo 44.2.a TRPLCSP y siempre que ostentase un interés legítimo en la anulación de determinada cláusula [o cláusulas] del mismo que no le impedía participar en el procedimiento pero le podía resultar perjudicial. Incluso si entendiéramos que la impugnación no estaba sujeta a plazo por tratarse de un vicio de nulidad de pleno derecho, es contrario a la buena fe que debe presidir la vida del contrato el que (...) consienta el pliego aceptando el procedimiento de contratación pública mediante la propia participación aspirando a la adjudicación y luego, al no resultar adjudicataria, y para optar de nuevo a la adjudicación en las mismas [o peores, porque pretende una mayor publicidad del anuncio de licitación] condiciones, impugne la adjudicación porque el acto administrativo consentido -el pliego- es contrario al ordenamiento jurídico alegando que su anulación la situaría de nuevo como candidata a la adjudicación. Esto resulta, además, contrario a la seguridad jurídica a cuya preservación tiende la firmeza de los actos para quien los consintió". 
2. Respecto a la habilitación profesional, la contratación de servicios propios de seguridad con subcontratación de servicios de conexión o mantenimiento de alarmas dan lugar a recursos. Entendemos que la normativa sectorial debe ser más clara al respecto admitiendo la subcontratación con empresas siempre que estén autorizadas.

3. De igual modo, se han planteado recursos por la exigencia en el pliego de servicios de seguridad de servicios auxiliares, admitiéndose la subcontratación.

4. Sobre disponibilidad de medios, se ha analizado un recurso sobre la adscripción al servicio de una cámara acorazada de seguridad, como criterio de valoración, en el que el Tribunal considera que es posible dicho criterio.

5. Se ha considerado procedente, como criterio de solvencia, además de acreditar haber realizado tres trabajos de seguridad y vigilancia, que se deban acreditar los propios de auxiliares de sala y de transporte de caudales.

6. Respecto a la solvencia técnica, se ha analizado cómo la exigencia de la propiedad de un Centro de Operaciones de Seguridad constituye un requisito de solvencia desproporcionado. Además, se ha comentado la improcedencia de exigir determinados certificados de calidad como criterio de adjudicación, pero admitiéndose la posibilidad de establecerlos como requisito de solvencia técnica.

7. Respecto a la exigencia como criterio de valoración de disponer de más de 2000 empleados de seguridad privada en la Comunidad de Madrid, se ha considerado por los Tribunales desproporcionado.

8. Respecto la experiencia del personal, también ha sido analizada la doctrina al respecto, no considerándose valorable el requisito de la antigüedad.

9. Se ha considerado que los criterios cualitativos podrán incluir, entre otros, aspectos sociales, porque estos evalúan la calidad.

10. La asignación de puntos a una mejora del sistema de remuneración y de la cuantía salarial de los trabajadores no se considera admisible.

11. Sobre el alcance de la información de subrogación en materia de seguridad, se han estudiado dos resoluciones específicas de servicios de seguridad y numerosas resoluciones generales de subrogación en contratos de servicios.

12. Sobre el ámbito de la discrecionalidad técnica en la valoración de ofertas de contratos de seguridad se han estudiado diversas resoluciones.

13. En relación con el alcance de la información privilegiada y la información adquirida en contratos anteriores se han examinado diversas resoluciones.

14. Se ha reflejado cómo los tribunales no pueden valorar medios personales distintos a los establecidos en el pliego. 
15. Se han estudiado resoluciones sobre ofertas con valores anormalmente bajos en especial en relación con la oferta de bolsas adicionales de horas de vigilancia, sin coste.

16. Se han visto resoluciones sobre ofertas que no alcanzan la puntuación mínima.

17. Se han referenciado ofertas que contienen error en su presentación electrónica y que por tanto han sido excluidas.

18. Se estudia el alcance de la modificación significativa de los pliegos en la fase de licitación a que se refiere el art. 136.2 de la LCSP y cómo el Tribunal considera que se ha modificado el Pliego en fase de licitación, infringiendo el principio de igualdad. 